\title{
Regulatory Non-coding RNAs in Atherosclerosis
}

\author{
Andreas Schober, Saffiyeh Saboor Maleki, and \\ Maliheh Nazari-Jahantigh
}

\section{Contents}

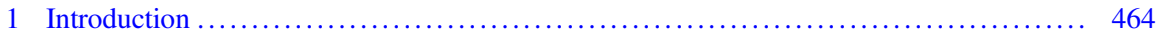

2 The Role of Non-coding RNAs in Arterial Endothelium ......................... 466

2.1 miRNAs Drive Inflammatory Activation in Dysadapted Arterial ECs ........... 467

2.2 The miR-126 Strands in Apoptosis and Regeneration of Dysadapted ECs ......... 470

2.3 The miR-103-lncWDR59 Axis Limits Endothelial Regeneration and Promotes Aberrant Proliferation ............................................. 471

3 Non-coding RNAs in Macrophage Function ............................... 472

3.1 Regulatory RNAs in Macrophage Energy and Lipid Metabolism ................ 473

$3.2 \mathrm{miR}-155-5 \mathrm{p}$ and miR-146a/b: The LPS Mediators in Atherosclerosis ............. 476

3.3 Regulatory RNAs Control Macrophage Death and Efferocytosis in Necrotic Core

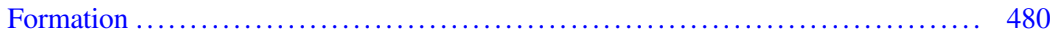

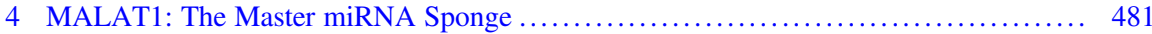

5 The Simian lncRNA ANRIL and the Risk Locus for Atherosclerosis ................ 482

6 Conclusions and Therapeutic Perspectives ................................. 483

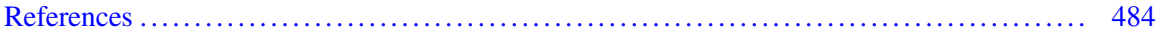

\section{Abstract}

Regulatory RNAs like microRNAs (miRNAs) and long non-coding RNAs (lncRNAs) control vascular and immune cells' phenotype and thus play a crucial role in atherosclerosis. Moreover, the mutual interactions between miRNAs and lncRNAs link both types of regulatory RNAs in a functional network that affects lesion formation. In this review, we deduce novel concepts of atherosclerosis from the analysis of the current data on regulatory RNAs' role in endothelial cells

\footnotetext{
A. Schober $(\bowtie) \cdot$ S. S. Maleki · M. Nazari-Jahantigh Institute for Cardiovascular Prevention, University Hospital, Ludwig-Maximilians-University, Munich, Germany

e-mail: Andreas.Schober@med.uni-muenchen.de; saffiyeh.saboor@med.uni-muenchen.de; mnazari@med.lmu.de
} 
(ECs) and macrophages. In contrast to arterial ECs, which adopt a stable phenotype by adaptation to high shear stress, macrophages are highly plastic and quickly change their activation status. At predilection sites of atherosclerosis, such as arterial bifurcations, ECs are exposed to disturbed laminar flow, which generates a dysadaptive stress response mediated by miRNAs. Whereas the highly abundant miR-126-5p promotes regenerative proliferation of dysadapted ECs, miR-103-3p stimulates inflammatory activation and impairs endothelial regeneration by aberrant proliferation and micronuclei formation. In macrophages, miRNAs are essential in regulating energy and lipid metabolism, which affects inflammatory activation and foam cell formation.

Moreover, lipopolysaccharide-induced miR-155 and miR-146 shape inflammatory macrophage activation through their oppositional effects on NF-kB. Most lncRNAs are not conserved between species, except a small group of very long lncRNAs, such as MALAT1, which blocks numerous miRNAs by providing nonfunctional binding sites. In summary, regulatory RNAs' roles are highly contextdependent, and therapeutic approaches that target specific functional interactions of miRNAs appear promising against cardiovascular diseases.

\section{Keywords}

Endothelial cell $\cdot$ Long non-coding RNA $\cdot$ Macrophage $\cdot$ MicroRNA

\section{Introduction}

RNA molecules have a great variety of functions in the cell, including the transfer of protein-coding information in the primary nucleotide sequence of the mRNA, reading the codons and matching them to amino acids by tRNA, catalysis of peptide bond formation by rRNA, and splicing of pre-mRNA by small nuclear RNAs in the spliceosome. Besides, regulatory non-coding RNAs, which have been grossly grouped into microRNAs (miRNAs) and long, non-coding RNAs (lncRNAs), play a critical role in the control of gene expression (Kopp and Mendell 2018). miRNAs have a comparatively confined length of 20-24 nucleotides and are processed from a primary transcript that contains a secondary hairpin structure with an imperfectly paired stem by endonucleases, such as Drosha and Dicer. By contrast, IncRNAs, linear and circular, are 200 to several thousand nucleotides long, which often adopt a complex secondary structure, and are generated in many different ways, such as RNaseP cleavage or back-splicing (Wu et al. 2017).

miRNAs play an essential role in nematodes, like miRNA let-7, the second described miRNA, which is critical in the development of $C$. elegans (Roush and Slack 2008). The nucleotides 2-7 at the $5^{\prime}$ end of the miRNA, also known as the "seed sequence," bind via Watson-Crick-based complementary base pairing to the recognition element mostly located in the $3^{\prime}$-UTR of mRNAs (Bartel 2018). However, also non-canonical interactions, including, e.g., G:U wobbles or bulges, can occur and mediate the effect of miRNAs (Chipman and Pasquinelli 2019). Thus, the 
seed sequence is essential for the function of miRNAs. Notably, some miRNAs share the same seed sequence but differ in one or two nucleotides outside the seed sequence, establishing a seed family of miRNAs. Moreover, multiple genomic loci may exist for a specific miRNA. For example, the human let-7 seed family, e.g., comprises 12 miRNAs, such as let-7a, let-7b, let-7c, etc., which share the same seed sequence (Lee et al. 2015). Moreover, three genomic loci encode the let-7a miRNA (let-7a-1, let-7a-2, and let-7a-3). Because of the same seed sequence, miRNA families may form a redundant system resistant to genetic losses and mutations.

Dicer cleaves the apical loop of the precursor hairpin and produces a miRNA duplex that contains the $5 \mathrm{p}$ (miRNA from the $5^{\prime}$ end of the precursor miRNA) and the $3 p$ strand of the mature miRNA. Following cleavage of the precursor miRNA hairpin by Dicer in the cytoplasm, a miRNA duplex is loaded to Argonaute proteins constituting the RNA-induced silencing complex (RISC). The two miRNA strands are separated, and one of the two strands exits the RISC. Argonaute proteins present the seed sequence of the retained miRNA strand in the mature RISC, and thus greatly enhance the interaction with the mRNA target sequence. Following binding of the target, miRNAs mediate either translational inhibition or degradation of the target mRNA through GW182 proteins (Schober and Weber 2016). Many miRNAs target hundreds of mRNAs in a cell, but the level of suppression rarely exceeds $50 \%$. An increase in miRNA genes parallels the development of vertebrates (Fromm et al. 2015). In humans, the number of miRNA genes expanded by 179 genes after the split from mouse, peaking at 585 miRNA genes with even many more mature miRNAs (Fromm et al. 2015). Therefore, miRNAs may play a role in the evolution of morphological complexity, probably by shaping specific cell phenotypes through buffering variations in gene expression due to environmental cues and internal noise (Kosik 2010; Siciliano et al. 2013). Thus, regulation by miRNAs confers robustness to differentiation processes during development (Ebert and Sharp 2012).

lncRNAs are not a homogenous class of molecules, but rather a mixture of different functional types with distinct biological mechanisms (Chen et al. 2016a). For example, a lncRNA can affect gene expression by the transcription of its genomic locus, by regulating chromatin states, influencing nuclear structure and organization, and interacting with and controlling proteins or other RNA molecules (Kopp and Mendell 2018; Yao et al. 2019). Many lncRNAs are biochemically identical to mRNAs, harboring a $5^{\prime}$ cap and a $3^{\prime}$ polyadenylated tail, and alternative splicing can produce numerous lncRNA transcripts. Whereas many miRNAs are highly conserved between species, most IncRNAs are evolutionary "novel" (< 50 Million years), and conservation even between humans and mice is rare (Ulitsky 2016). In humans, around 50-90,000 genomic lncRNA loci are annotated (Ulitsky 2016; Uszczynska-Ratajczak et al. 2018), the majority is expressed at a very low level and may not play a functional role. However, a small group of very long, highly expressed, and evolutionarily conserved lncRNAs exists, including, e.g., metastasisassociated lung adenocarcinoma transcript (MALAT) 1 and myocardial infarction associated transcript (MIAT). Notably, these lncRNAs contain binding sites for a large number of miRNAs and interact with those in the RISC, the so-called sponge effect. Numerous reports have shown that the functional effect of sponging lncRNAs 
is due to the inhibition and suppression of the bound miRNAs. Thus, sponging miRNAs appears to be an evolutionarily conserved function of this group of lncRNAs, which closely links the miRNA and the lncRNA world in a complex interaction network.

\section{The Role of Non-coding RNAs in Arterial Endothelium}

The arterial system is inherently vulnerable to chronic, low-grade endothelial injury at branching sites and curvatures due to disturbed laminar blood flow (Chen et al. 1997). Considering the specifications of ECs in different vascular regions and organs, the response of arterial ECs to non-laminar blood flow appears as if they are maladapted to this physiologic condition at branching arteries. Whereas the low shear stress generated by non-laminar blood flow is stable, the direction of the shear stress and blood flow near the arterial wall in these regions changes randomly, indicating complex vortices. Accordingly, ECs do not align to the direction of the blood flow at branching sites like at arterial areas exposed to laminar blood flow (Gau et al. 1980).

Interestingly, the multidirectionality of near-wall shear stress better predicts the effect of non-laminar blood flow on the localization of atherosclerotic lesions than low shear stress (Peiffer et al. 2013; Mohamied et al. 2015, 2017). Because cellular adaptation to chaotic conditions is impossible, the unpredictable changes of the shear stress direction prevent the adaptation of arterial ECs to non-laminar blood flow and trigger a heterogeneous stress response (Fig. 1). Although at a low frequency, the non-laminar blood flow induces apoptosis of ECs by activating the endoplasmatic reticulum stress response and SUMOylation of p53 (Kim and Woo 2018; Bjorkerud and Bondjers 1972; Zeng et al. 2009; Pan et al. 2017; Hansson et al. 1985; Heo et al. 2011, 2013). Apoptotic ECs are rapidly replaced by the migration and proliferation of adjacent ECs. The endothelial dysadaptation to disturbed laminar blood flow also triggers inflammatory activation and increased adhesiveness to leukocytes, which may play a role in endothelial repair (Tsao et al. 1995). Stress-induced transcription factors, such as NF- $\kappa b$ and hypoxia-inducible factor (HIF)- $1 \alpha$, shape the inflammatory phenotype of dysadapted arterial ECs (Akhtar et al. 2015).

Moreover, chronic endothelial healing in arterial regions exposed to disturbed laminar blood flow impairs endothelial barrier function and increases the permeability to macromolecules, such as lipoproteins (Mundi et al. 2018). Low-density lipoproteins (LDL) are trapped in the subendothelial space and become oxidized by ECs (van Hinsbergh et al. 1986). Oxidized LDL constitutes the second cause of endothelial death (Salvayre et al. 2002) and drives the accumulation of monocytederived macrophages in the vessel wall. In arterial regions exposed to laminar blood flow, which stimulates the expression of the transcription factors Krüppel-like factor (KLF) 2 and KLF4, endothelial turnover and vascular permeability are low (Gerrity et al. 1977). KLF2 and KLF4 contribute to a quiescent endothelial phenotype by regulating up to $15 \%$ of the flow-regulated genes in a partially redundant manner resulting in the reduction of vascular permeability, inflammatory gene expression, and thrombogenicity (Schober et al. 2015). Moreover, high shear stress-exposed 


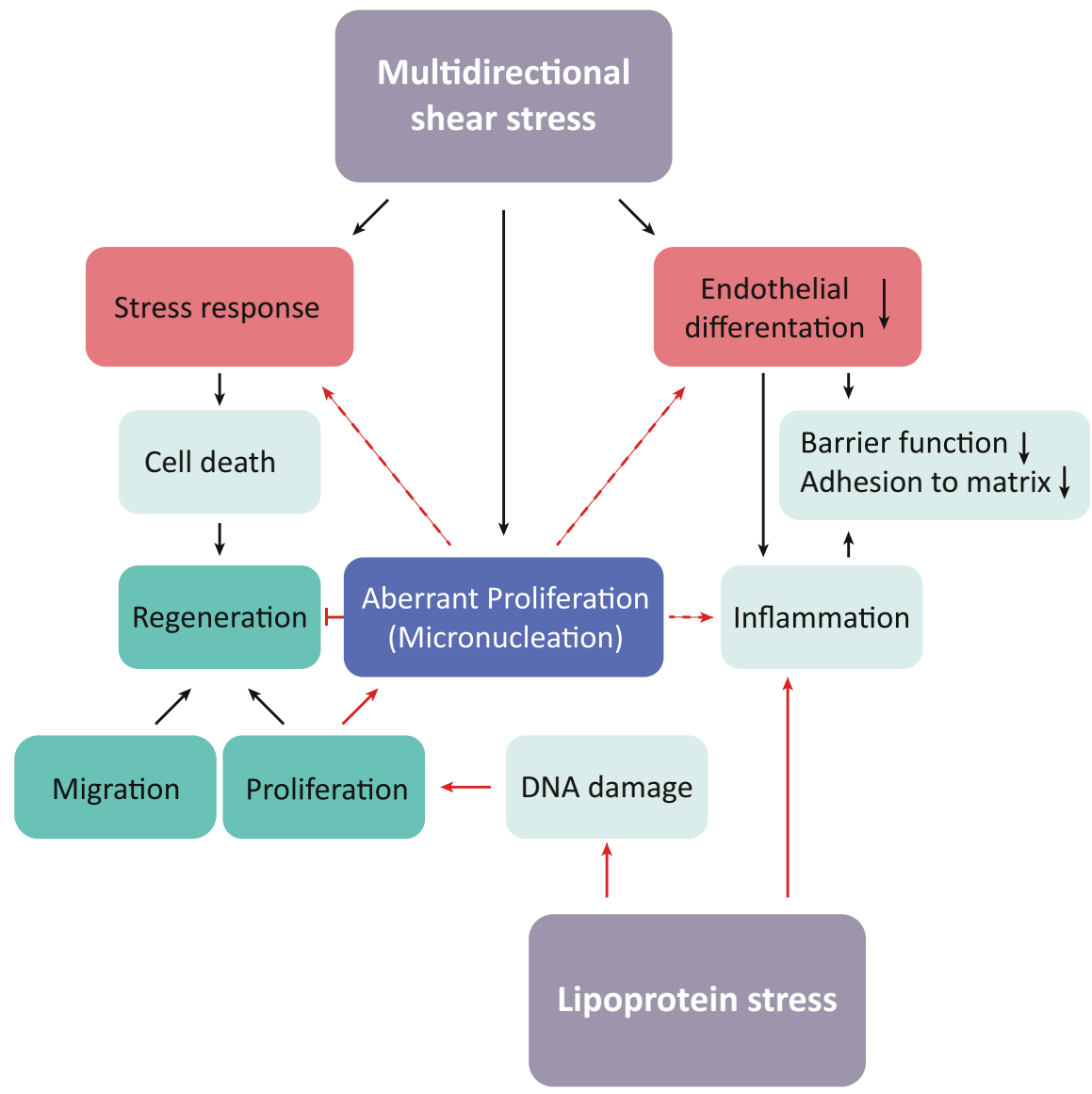

Fig. 1 Dysadaptation of arterial ECs sensitizes to lipoprotein stress. The unpredictable changes in the direction of near-wall shear stress and blood flow at arterial bifurcations make the adaptation of arterial ECs impossible. The dysadaptation induces a stress response characterized by EC death and a lack of endothelial differentiation. The damaged endothelium is regenerated by migrating and proliferating ECs; however, the chronic endothelial wound healing poses a risk for aberrant proliferation due to DNA damage of mitotic ECs by oxidative lipoprotein stress. Dashed lines indicate hypothetical effects

ECs can rapidly proliferate and regenerate the endothelium in response to acute injury (Hansson et al. 1985).

\section{1 miRNAs Drive Inflammatory Activation in Dysadapted Arterial ECs}

ECs express 164 to 315 miRNAs, and the miRNA expression profile differs significantly between ECs from different vascular regions (McCall et al. 2011; Voellenkle 
et al. 2012). miR-21-5p (32\% of all endothelial miRNAs) is by far the most abundant miRNA in human umbilical vein ECs, followed by miR-126-3p (7\%) (Voellenkle et al. 2012). Surprisingly, Mir21 knockout mice do not have any gross phenotypic changes and develop normally (Patrick et al. 2010). By contrast, 50\% of all Mir126 knockout mice die during development due to vascular leakage, but the surviving mice develop normally (Kuhnert et al. 2008). Notably, specific miRNA families and clusters are primarily expressed in ECs, such as the miR-221/222 cluster, the let-7 miRNA family, and the miR-17-92 cluster. Endothelial Dicer is not essential in embryonic development, and, surprisingly, Dicer suppresses endothelial differentiation in vitro by downregulating KLF2 and by upregulating inflammatory genes, such as CXCL1 and IL-8 (Suarez et al. 2007, 2008; Wu et al. 2011). Accordingly, knockout of endothelial Dicer in $A p o e^{-/-}$mice limits endothelial inflammation and atherosclerotic lesion formation (Hartmann et al. 2016; Natarelli et al. 2018), indicating that the whole miRNA system counter regulates high shear stress-induced endothelial differentiation. This effect was associated with the downregulation of a relatively small subset of miRNAs, including miR-103-3p, miR-652-3p, and miR-433-3p, whereas miR-126-3p was not reduced, indicating substantial differences in the turnover rates of these miRNAs. In general, the stability of miRNAs is more than ten times higher than that of mRNAs; however, turnover rates significantly differ between individual miRNAs (Hartmann et al. 2016; Gantier et al. 2011). Thus, the role of endothelial Dicer in atherosclerosis and endothelial differentiation may depend on the generation of miRNAs with a short half-life. Similar to the in vitro results, endothelial Dicer increases inflammatory gene expression, such as $\mathrm{Cxcl} 1$ and $\mathrm{Ccl} 2$, and reduces the expression of endothelial genes such as cadherin 5 and SRY-box transcription factor (Sox) 17, in murine atherosclerotic arteries. Also, Dicer significantly regulates KLF4, Notch, and $\beta$-catenin signaling pathways in atherosclerotic ECs (Hartmann et al. 2016).

miR-103-3p mediates many of the inflammatory effects of Dicer in ECs (Hartmann et al. 2016). The Mirl03 gene is expressed from two different genomic loci located in the intronic sequences of the pantothenate kinase (Pank) 2 and Pank3 genes. These genomic loci and the sequence of the mature miR-103-3p are highly conserved within deuterostomes (Finnerty et al. 2010). Notably, miR-103-3p is abundant in ECs at branching sites of arteries, probably due to disturbed flowinduced NF- $\kappa$ B activation (Hartmann et al. 2016; Tzima et al. 2005). Hyperlipidemia and mildly oxidized LDL also upregulate miR-103-3p expression in arterial ECs (Hartmann et al. 2016). miR-103-3p promotes dedifferentiation by targeting KLF4 and increases Cxcl1-dependent monocyte recruitment to atherosclerotic arteries. Accordingly, inhibiting the interaction between miR-103-3p and KLF4 with a sequence-specific oligonucleotide ameliorates atherosclerosis (Hartmann et al. 2016). Moreover, inhibition of miR-103-3p also reduces atherosclerosis, endothelial inflammation, and endoplasmic reticulum stress in Apoe $e^{-/-}$mice (Jiang et al. 2020). In human aortic ECs, miR-103-3p targets phosphatase and tensin homolog (PTEN) through a canonical binding site, which is not conserved in mouse (Jiang et al. 2020).

In addition to miR-103-3p, the expression of miR-652-3p in ECs promotes atherosclerosis (Huang et al. 2019). The development of atherosclerosis is reduced 
in Mir652 $2^{-/-} / \mathrm{Apoe}^{-/-}$mice, probably due to increased endothelial regeneration, because miR-652-3p inhibits endothelial proliferation and repair following mechanical injury (Huang et al. 2019). miR-652-3p suppresses endothelial proliferation by targeting the G1 cyclin, cyclin D2 (Ccnd2) in human and mouse via different non-canonical sites, indicating functional conservation of this interaction (Huang et al. 2019). Ccnd 2 is targeted by two other miRNAs, miR-494, and the let-7 family member miR-98, in ECs, which thereby inhibit endothelial proliferation ( $\mathrm{Li}$ et al. 2016; Wu et al. 2016). Besides, the expression of miR-652-3p inversely correlates with the endothelial expression of CCND2 and EC proliferation in human atherosclerosis, suggesting that miR-652-3p plays a vital role in endothelial dysadaptation (Huang et al. 2019).

miR-92a-3p is another important miRNA in endothelial dysadaptation and inflammation, which is, like miR-103-3p, upregulated in ECs by low shear stress, oxidized LDL, and oxidative stress (Chen et al. 2015; Fang and Davies 2012). miR-92a-3p cooperates with miR-103-3p in suppressing KLF4 and enhancing inflammatory gene expression through activation of NF- $\mathrm{kB}$. Moreover, miR-92a$3 p$ targets several other transcripts in ECs, like KLF2, SOCS5, and SIRT1 (Chen et al. 2015), which also contributes to the inflammatory phenotype of dysadapted ECs. Accordingly, inhibition of miR-92a-3p by antisense oligonucleotides in Apoe ${ }^{-1}$ - and $\mathrm{Ldlr}^{-1-}$ mice reduced atherosclerosis and endothelial inflammation (Chen et al. 2015; Loyer et al. 2014). However, after subtotal nephrectomy in Apoe ${ }^{-/-}$mice on a regular diet, as a model of atherosclerosis triggered by chronic renal failure, locked nucleic acid-based inhibitors of miR-92a-3p applied together with HDL did not reduce lesion formation, despite a strong decrease in endothelial miR-92a-3p expression (Wiese et al. 2019). This result indicates that the role of endothelial miR-92a-3p in atherosclerosis may be model dependent. ECs also release miR-92a$3 p$ in microvesicles, which increases the level of miR-92a-3p in the circulation of patients with coronary atherosclerosis (Liu et al. 2019). miR-92a-3p is processed from the 7-kb long lncRNA MIR17HG together with five other miRNAs, including miR-17-5p, miR-18a-5p, miR-20a-5p, miR-19a-3p, and miR-19b-3p (Mogilyansky and Rigoutsos 2013). Whereas miR-92a and miR-19b are additionally processed from the miR-106a-363 cluster transcript, miR-19a is only expressed from the miR-17-92a locus. Activation of HIF-1 $\alpha$ in arterial ECs by turbulent flow and lipoprotein-derived lysophosphatidic acid selectively upregulates miR-19a-3p (Akhtar et al. 2015). Because HIF-1 $\alpha$-mediated miR-19a-3p expression in ECs increases monocyte adhesion by activating NF- $\mathrm{kB}$, this mechanism may mediate the atherogenic effect of endothelial HIF-1 $\alpha$ activation (Akhtar et al. 2015). Accordingly, blocking miR-19a-3p by systemic injection of antisense oligonucleotides decreases atherosclerosis in Apoe $e^{-1-}$ mice (Chen et al. 2017).

The miR-106b-25 cluster contains three miRNAs, including miR-106b, miR-93, and miR-25, and closely relates to the miRNAs of the miR-17-92a locus. Whereas miR-106b and miR-25 belong to the miR-17 family of miRNAs, miR-25 shares the same seed sequence with miR-92a (Mogilyansky and Rigoutsos 2013). Knockout of the miR-106b-25 cluster in Apoe ${ }^{-/-}$mice decreases atherosclerosis, reduces the cholesterol content in VLDL and LDL in the blood, and increases VLDL and LDL 
receptor expression in splenocytes (Semo et al. 2019). These findings indicate that the miRNAs of the miR-106b-25 cluster elevate plasma lipid levels by suppressing lipoprotein clearance by the spleen (Semo et al. 2019).

\subsection{The miR-126 Strands in Apoptosis and Regeneration of Dysadapted ECs}

MiR-126-3p is one of the most highly expressed miRNAs in ECs. Apoptosis triggers the packaging of miR-126-3p into apoptotic bodies, which are released to the extracellular space, and adjacent ECs take up the apoptotic vesicles. The paracrine transfer of miR-126-3p from apoptotic ECs upregulates the chemokine CXCL12 in the recipient ECs and reduces atherosclerosis (Zernecke et al. 2009). However, the role of CXCL12 and its receptor CXCR4 in atherosclerosis is ambiguous. Whereas endothelial knockout of CXCL12 decreases lesion formation, deletion of its receptor CXCR4 in ECs promotes atherosclerosis (Döring et al. 2017, 2019). These findings suggest that the absence of endothelial CXCL12 expression, which reduces circulating CXCL12 levels, limits lipid deposition in the arterial wall, probably due to its inhibitory effect on cholesterol efflux from macrophages (Gao et al. 2019a). By contrast, local delivery of miR-126-3p in apoptotic vesicles to ECs may support endothelial function by CXCR4-mediated activation of the AKT pathway (Döring et al. 2017). Interestingly, miR-126-3p increases AKT signaling in ECs (Chen et al. 2016b; Fish et al. 2008), reduces endothelial apoptosis, and supports endothelial barrier function (Döring et al. 2017; Cheng et al. 2017a). Several miR-126-3p targets, such as RGS16, phosphatidylinositol 3-kinase regulatory subunit beta, and transforming growth factor- $\beta$ may play a role in the protection of ECs from apoptosis.

Processing of the precursor miR-126 by Dicer also produces a mature miRNA from its $5 p$ end. Although the miR-126-5p expression level is lower than that of miR-126-3p, it is still one of the most highly expressed miRNAs in ECs. Disturbed laminar flow suppresses miR-126-5p expression in dysadapted ECs and limits, thereby their capacity to compensate additional hyperlipidemia-induced injury by increased proliferation (Schober and Weber 2016). Conversely, higher miR-126-5p levels in ECs exposed to laminar flow increase their proliferative reserve compared with dysadapted ECs (Schober et al. 2014). miR-126-5p generates an endothelial proliferative reserve by suppressing delta like non-canonical notch ligand (DLK) 1, an inhibitor of the Notch1 signaling pathway (Schober et al. 2014). Derepression of DLK1 in dysadapted ECs limits endothelial regeneration in response to hyperlipidemic stress (Fig. 2). Thus, inhibition of miR-126-5p expression in ECs by disturbed flow promotes atherosclerosis (Schober et al. 2014). The inhibition of Notch1 may at least partially mediate the effects of DLK1. Accordingly, disturbed flow reduces endothelial Notch1 activation, and knockout of Notch1 in ECs increases lesion formation (Mack et al. 2017). Moreover, high shear stress reduces endothelial apoptosis by miR-126-5p-mediated inhibition of caspase 3 in the nucleus (Santovito et al. 2020). These results indicate a dual role of miR-126-5p in ECs; in 


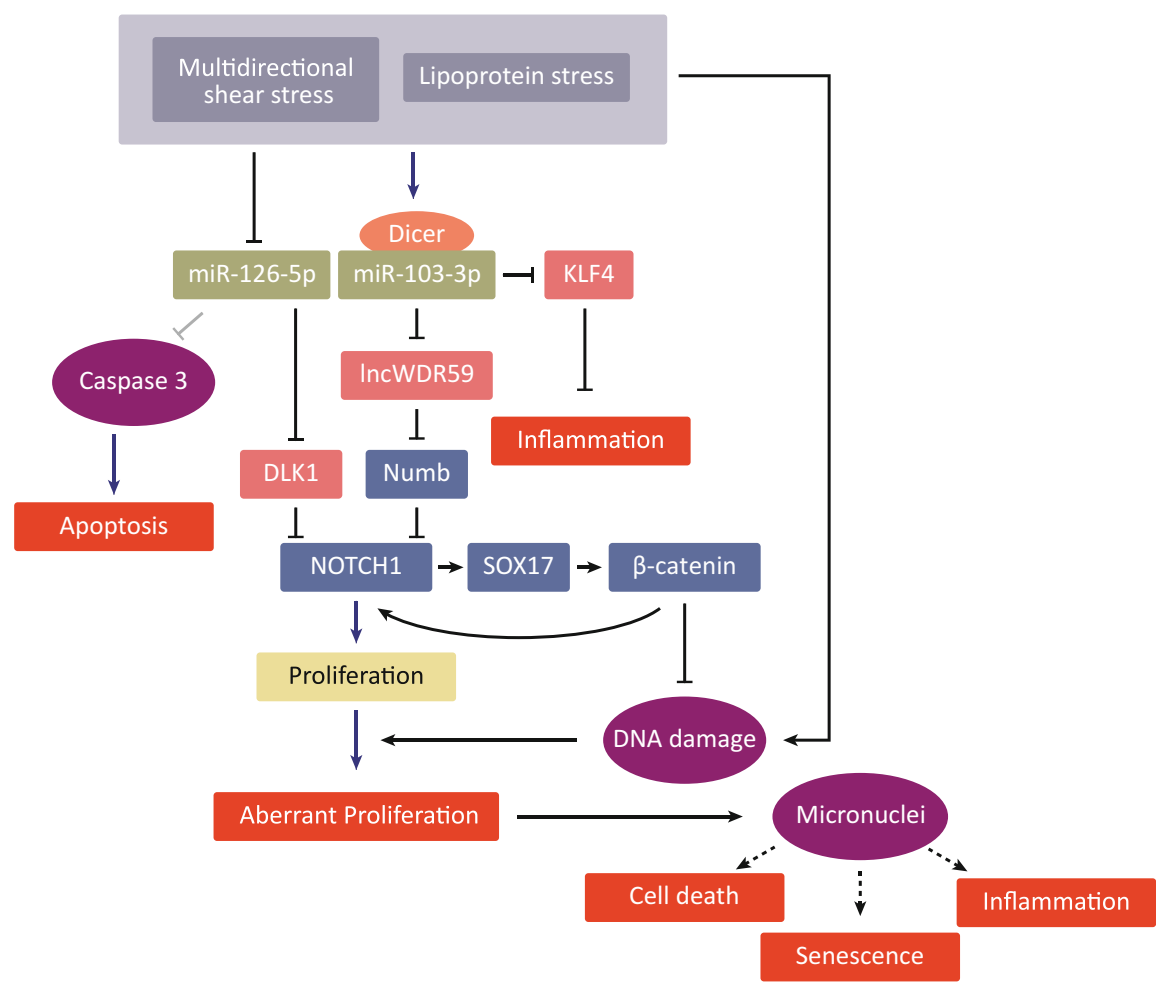

Fig. 2 miRNAs modulate endothelial dysadaptation. The protective miR-126-5p is downregulated in dysadapted ECs, which limits NOTCH1-mediated endothelial regeneration and increases EC apoptosis through a non-canonical mechanism. By contrast, Dicer produces increased levels of miR-103 in dysadapted ECs, which promotes inflammation by targeting KLF4. Moreover, miR-103 inhibits EC proliferation and promotes DNA damage, thus impairing the chronic wound healing response of dysadapted ECs

the cytoplasm, it facilitates Notch1 signaling and thus promotes endothelial regeneration; in the nucleus, it limits apoptosis through a non-canonical mechanism.

\subsection{The miR-103-IncWDR59 Axis Limits Endothelial Regeneration and Promotes Aberrant Proliferation}

In arteries, endothelial repair by proliferation is a delicate process because blood flow can detach mitotic ECs and increase vascular permeability (Wechezak et al. 1994). Moreover, mitotic cells are incredibly vulnerable to DNA damage because double-strand breaks cannot be repaired and may lead to errors in chromosomal segregation and the formation of micronuclei consisting of chromatin surrounded by its nuclear membrane (Blackford and Stucki 2020). Chromosomes in micronuclei accumulate DNA damage and replicate imperfectly, leading to genomic instability, 
which can induce growth arrest, senescence, apoptosis, and inflammation (Blackford and Stucki 2020; Zhang et al. 2015; Shah and Bennett 2017). Atherogenic LDL triggers DNA damage in aortic ECs in a LOX-1-dependent manner, probably by increasing mitochondrial ROS production (Wang et al. 2018). Moreover, chronic inflammation may enhance DNA damage due to environmental exposures in tissues that are continuously regenerating (Kiraly et al. 2015). Thus, aberrant proliferation characterized by DNA damage and micronuclei formation may impair chronic regeneration of dysadapted arterial ECs and promote atherosclerosis. Accordingly, high-fat diet (HFD) feeding enhances micronuclei formation and DNA damage in ECs, primarily at predilection sites of atherosclerosis (Natarelli et al. 2018; Thum and Borlak 2008). This finding indicates that disturbed laminar blood flow and oxidized LDL synergistically promote genomic instability (Fig. 1).

In addition to inflammation, Dicer increases DNA damage and micronuclei formation in ECs and inhibits endothelial proliferation at predilection sites of atherosclerosis (Natarelli et al. 2018). These effects are due to the suppression of the IncRNA lncWDR59 by miR-103-3p. lncWDR59 promotes Notch1 activation and endothelial proliferation by competitive binding to the Notch1 inhibitor Numb (Natarelli et al. 2018). Moreover, Notch1 induces SOX17 expression and thus increases $\beta$-catenin activity, which inhibits oxLDL-mediated DNA damage and micronuclei formation in ECs. Therefore, the interaction between miR-103-3p and lncWDR59 promotes aberrant EC proliferation by abolishing $\beta$-catenin-mediated protection against DNA damage. Accordingly, blocking the targeting of lncWDR59 by miR-103-3p in $\mathrm{Apoe}^{-1-}$ mice reduces atherosclerosis and endothelial DNA damage and increases endothelial proliferation (Fig. 2). Notably, a human lncWDR59 homolog with a conserved genomic location exists. In human lesions, ECs express lncWDR59, and its expression level correlates with endothelial proliferation, indicating that the targeting of lncWDR59 by miR-103-3p also plays a role in humans (Natarelli et al. 2018).

\section{$3 \quad$ Non-coding RNAs in Macrophage Function}

Macrophages drive the progression of atherosclerosis from a clinically silent condition to advanced lesions with a thrombogenic core. Uncontrolled uptake of modified lipoproteins from the extracellular space by macrophages promotes their transformation into foam cells characterized by the accumulation of cholesterol esters and triglycerides in lipid droplets, similar as in adipocytes. Whereas cholesterol is removed from foam cells by ATP binding cassette subfamily A member (ABCA) 1 and ATP binding cassette subfamily $\mathrm{G}$ member (ABCG) 1 transporters, triglycerides and fatty acids can be degraded by foam cells and fuel mitochondrial energy production. However, the ongoing influx of lipoproteins exceeds the capacity of macrophages to store cholesterol intracellularly or transfer it to HDL, which causes cell death and the formation of cholesterol crystals. Accordingly, macrophages death by apoptosis or necroptosis increases during the progression of atherosclerosis (Lin et al. 2013). Besides, the phagocytic removal of dying foam 
cells is impaired or insufficient in advanced atherosclerosis resulting in the formation of a lipid-rich, necrotic core with cholesterol crystals encapsulated by macrophages.

In contrast to arterial ECs, which have a more stable phenotype, macrophages undergo considerable phenotypic changes during inflammatory activation. Bacterial products such as lipopolysaccharide (LPS) and the $\mathrm{T}_{\mathrm{h}} 1$ cell cytokine IFN $\gamma$ activate the NF- $\kappa$ B and HIF- $1 \alpha$ pathway and thus shift mitochondrial function from energy production to the generation of reactive oxygen species (ROS) and reactive nitrogen species (RNS) to combat microbes (Cameron et al. 2019). In turn, energy production is shifted to aerobic glycolysis, which reduces ATP supply. By contrast, stimulation with IL-4 evokes a different response characterized by signal transducer and activator of transcription (STAT) 6 and peroxisome proliferator-activated receptor (PPAR) activation, which reduces nitric oxide (NO) and promotes mitochondrial ATP production by oxidative phosphorylation (OXPHOS) of fatty acids. The latter effect may support phagocytosing macrophages, which need more energy and are challenged by the influx of lipids.

\subsection{Regulatory RNAs in Macrophage Energy and Lipid Metabolism}

miR-10a-5p, miR-146a-5p, and let-7 family members, and miR-21a-5p are among the most abundant miRNAs in murine macrophages (Canfran-Duque et al. 2017). Dicer knockout reduces the expression of a great majority of miRNAs in macrophages, including miR-21a-5p, miR-342-5p, miR-10a-5p, and miR-503-5p (Wei et al. 2018). In contrast to ECs, knockout of Dicer in macrophages increases the development of atherosclerosis, macrophage apoptosis, and the expression of NOS2 and inflammatory cytokines, such as IL-1 $\beta$ (Wei et al. 2018). Moreover, Dicer knockout impairs OXPHOS in IL-4 stimulated but not in unstimulated or LPS/IFN$\gamma$-stimulated macrophages, suggesting a central role of miRNAs in the energy metabolism of IL-4-stimulated, anti-inflammatory macrophages (Wei et al. 2018). Notably, Dicer also increases oxygen consumption and mitochondrial oxidation in macrophage-derived foam cells, and thus limits the accumulation of lipids probably by the oxidation of fatty acids (Wei et al. 2018). Ligand-dependent corepressor (LCOR) is a crucial target of miRNAs in macrophages and contains numerous highly conserved miRNA-binding sites in its $3^{\prime}$-UTR. LCOR inhibits retinoid X receptor alpha (RXRA), which promotes the expression of OXPHOS-related genes and increases mitochondrial function through interaction with peroxisome proliferator-activated receptor-gamma coactivator (PGC)-1 (Chae et al. 2013). Among the miRNAs predicted to target LCOR, miR-10a-5p most strongly promoted OXPHOS in IL-4-stimulated macrophages and foam cells through targeting LCOR (Wei et al. 2018). Moreover, miR-10a-5p increases OXPHOS also by interacting with another corepressor of nuclear receptors, nuclear receptor corepressor 2 (NCOR2), which inhibits the activity of the PPAR $\alpha$ (Wei et al. 2018). Blocking the interaction between miR-10a-5p and LCOR in macrophages by target sitespecific antisense oligonucleotides increases atherosclerosis in mice, suggesting 

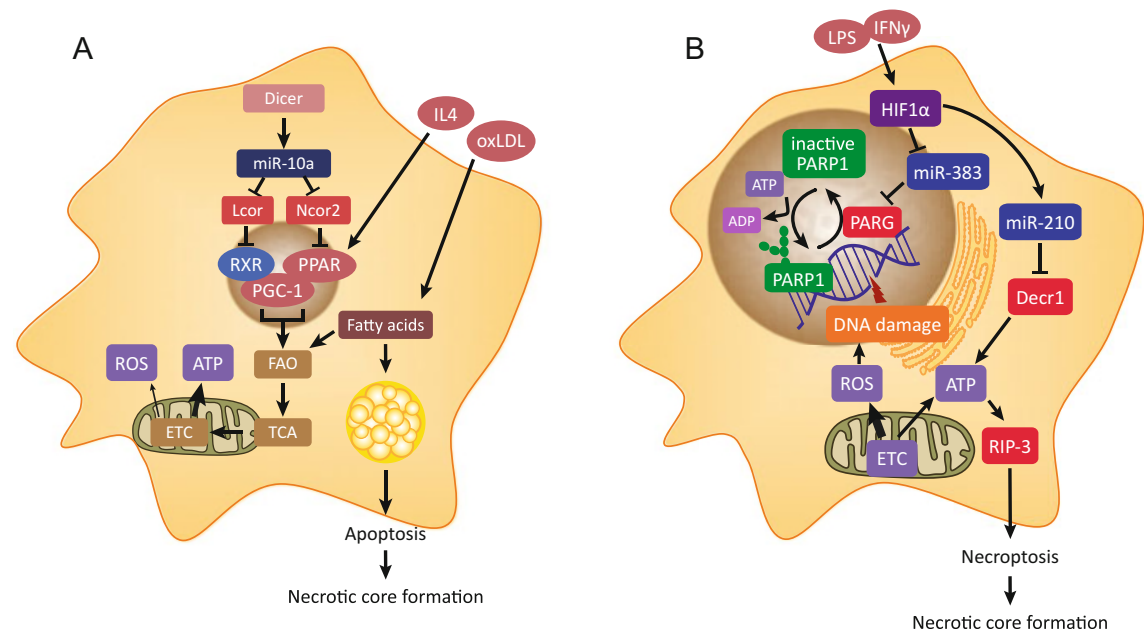

Fig. 3 Effects of miRNAs in macrophages on energy metabolism and cell death. (a) In antiinflammatory macrophages, Dicer promotes mitochondrial energy production by generating miR-10a, which targets the corepressors of nuclear receptors, such as LCOR and NCOR2. miR-10a improves fatty acid oxidation (FAO) and reduces foam cell formation, thus enhancing cell survival. (b) In inflammatory macrophages, HIF-1 $\alpha$ activation switches the mitochondrial metabolism from ATP to ROS production, thus generating a pseudo-hypoxic state. This effect of HIF- $1 \alpha$ is mediated by the suppression of Decr1 by miR-210, which reduces ATP synthesis and necroptotic cell death. Moreover, HIF-1 $\alpha$ activation lowers cellular ATP levels by hyper activating PARP-1 due to the derepression of the miR-383 target PARG. ETC, electron transport chain; TCA, tri-carboxyl acid

that miRNA-mediated OXPHOS in macrophages protects from atherosclerosis (Wei et al. 2018). Notably, RXR $\alpha$ agonists upregulate miR-10a-5p in ECs, indicating a positive forward loop in which $\mathrm{RXR} \alpha$ increases its activity by miR-10a-5pmeditated suppression of LCOR (Lee et al. 2018). Moreover, treatment of Apoe ${ }^{-1}$ - mice with miR-10a-5p mimics reduces atherosclerosis (Lee et al. 2018). Besides let-7b-5p, but not other members of the let-7 family increases mitochondrial function, indicating that the functional role between the members of a miRNA family can differ despite having the same seed sequence (Fig. 3).

Hypoxia-inducible factor $1 \alpha(\mathrm{HIF}-1 \alpha)$ is an essential transcription factor in the regulation of mitochondrial energy metabolism in inflammatory macrophages. Stimulation of macrophages with LPS and IFN $\gamma$ activates HIF- $1 \alpha$, which generates a pseudo-hypoxic state by shutting down OXPHOS and increasing ROS and RNS production. Although this metabolic switch aids to fight off infections, the concomitantly reduced energy supply and enhanced exposure to oxidizing agents can lead to macrophage necroptosis (Pajuelo et al. 2018; He et al. 2011). In atherosclerotic lesions, HIF-1 $\alpha$ activation increases receptor-interacting serine/threonine kinase 3 (RIP3)-mediated macrophage necroptosis and necrotic core formation (Lin et al. 2013; Karshovska et al. 2020). This effect is probably mediated by HIF-1 $\alpha$-induced 
upregulation of miR-210, which lowers ATP levels by suppressing OXPHOS and increasing ROS through targeting 2,4-dienoyl-CoA reductase1 (Decr1) (Karshovska et al. 2020). Decr1 is an essential enzyme in the $\beta$-oxidation of unsaturated fatty acids and in the adaptation to metabolic stress during fasting (Miinalainen et al. 2009). Thus, $\beta$-oxidation of unsaturated fatty acids may be critical for the survival of energy-depleted inflammatory macrophages by maintaining a basal level of oxidative ATP production. miR-210 is highly abundant in human atherosclerosis, and HIF-1 $\alpha$ activation in macrophages increases lesional miR-210 expression in Apoe $^{-/-}$mice (Karshovska et al. 2020; Raitoharju et al. 2011). However, the functional role of miR-210 in atherosclerosis has not yet been studied.

Similar to LCOR, the $3^{\prime}$-UTR of the ABCA1 transcript contains numerous conserved binding sites for miRNAs, indicating a significant role of miRNAs in foam cell formation, efferocytosis, and inflammatory activation by regulating ABCA1 expression (Zannis et al. 2006; Wei and Schober 2016). In addition to the transcriptional regulation by the nuclear sterol-activated liver-X-receptors (LXRs), post-transcriptional targeting of the ABCA1 transcript by at least 15 miRNAs, such as miR-33-5p, miR-302a-3p, and miR-23a-3p, has been experimentally confirmed (Yang et al. 2018; Rayner et al. 2010; Meiler et al. 2015).

miR-33a-5p (only miR-33-5p in mice) is co-transcribed from an intronic region of the transcription factor sterol regulatory element-binding protein-2, and both synergistically promote cellular cholesterol accumulation in macrophages (Schober and Weber 2016). miR-33-5p is one of the most extensively studied miRNA in atherosclerosis, initially because blocking miR-33-5p raised HDL levels, an effect that is likely due to the targeting of ABCA1 in the liver. The role of miR-33-5p in atherosclerosis has been controversially discussed. Studies in genetically modified mice show conflicting results. In Apoe $e^{-/-}$mice, the whole-body knockout of the Mir33 gene reduces atherosclerosis, whereas the absence of miR-33-5p expression in bone marrow cells does not alter lesion formation (Horie et al. 2012). However, in $\mathrm{Ldlr}^{-/-}$mice, only deletion of Mir33 in bone marrow cells slightly reduces lesion formation, whereas the whole-body knockout of Mir33 surprisingly does not affect atherosclerosis (Price et al. 2017). These results indicate that the expression of miR-33-5p in bone marrow cells promotes atherosclerosis in $\mathrm{Ldlr}^{-/-}$mice, whereas its expression in non-bone-marrow cells is athero-protective. Interestingly, $\mathrm{Ldlr}^{-1-}$ mice with bone marrow cells that harbor a mutation of the miR-33-5p binding site in the ABCA1 3'-UTR develop less atherosclerosis, similar to the effect of the Mir33 knockout in bone marrow cells (Price et al. 2019). Although this mechanism can explain not all impacts of miR-33-5p, targeting of ABCA1 in macrophages appears to play a crucial role in atherogenesis in $\mathrm{Ldlr}^{-1-}$ mice.

miR-34a-5p is highly abundant in atherosclerotic lesions and targets ABCA1 and ABCG1 in macrophages (Xu et al. 2020). Interestingly, the ABCA1 and ABCG1 binding sites of miR-34a-5p are not conserved between human and mouse, and only the site in the human ABCA1 3'-UTR is canonical (Xu et al. 2020). This finding suggests that non-canonical sites are functional and that miRNA sites can have the same effect in mouse and human despite the lack of a conserved binding site. Consistently, the conditional knockout of Mir34a in myeloid cells and the knockout 
of Mir34a in bone marrow cells reduces atherosclerosis in $\mathrm{Apoe}^{-/-}$and $\mathrm{Ldlr}^{-/-}$ mice, respectively (Xu et al. 2020). This effect has been attributed to improved cholesterol efflux from macrophages due to increased expression of ABCA1, ABCG1, and LXR $\alpha$.

Notably, several ABCA1-targeting miRNAs promote lesion formation in atherosclerotic mouse models, such as miR-302a-3p (Meiler et al. 2015), miR-23a-5p (Yang et al. 2018), miR-17-5p (Tan et al. 2019), miR-20a/b-5p (Liang et al. 2017), and miR-19b-5p (Lv et al. 2014). However, it is unclear whether the effects of these miRNAs on lesion formation are due to ABCA1 suppression.

LXR activation induces not only ABCA1 expression but also upregulates several lncRNAs, which further increase ABCA1 levels. For example, the primate-specific lncRNA cholesterol homeostasis regulator of miRNA expression (CHROME) is upregulated in atherosclerotic lesions and derepresses ABCA1 expression by inactivating several ABCA1-targeting miRNAs, such as miR-27b, miR-33a/b, and miR-128 (Hennessy et al. 2019). Another LXR-induced lncRNA is macrophageexpressed LXR-induced sequence (MeXis), which is transcribed from a gene located near the ABCA1 gene (Sallam et al. 2018). MeXis acts as a nuclear RNA that influences chromatin architecture and facilitates the accessibility of the nuclear receptor coactivator DDX17 at the ABCA1 locus, thus enhancing LXR-mediated ABCA1 expression in response to cholesterol loading in macrophages (Sallam et al. 2018). Knockout of MeXis in bone marrow cells reduces atherosclerosis and increases ABCA1 expression in $\mathrm{Ldlr}^{-1-}$ mice (Sallam et al. 2018). Notably, a genomic region surrounding the MeXis/ABCA1 locus revealed some degree of conservation between species. In humans, a non-coding RNA transcript in this region was identified as TCONS00016111 with some sequence conservation with MeXis (Sallam et al. 2018). However, its role in lipid metabolism in human lesional macrophages is not fully understood.

\section{2 miR-155-5p and miR-146a/b: The LPS Mediators in Atherosclerosis}

miR-155-5p is a highly conserved miRNA and predominantly expressed in hematopoietic cells, such as lymphocytes and macrophages. The precursor miR-155 hairpin is encoded in the third exon of a lncRNA called MIR155HG. The expression of MIR $155 \mathrm{HG}$ is driven by a promoter that is strongly activated by NF-кB (Schober and Weber 2016; Thompson et al. 2013). Thereby, LPS selectively induces miR-155-5p in macrophages together with a small number of other miRNAs, such as miR-147-5p and miR-210-5p (Androulidaki et al. 2009; Nazari-Jahantigh et al. 2012; Dueck et al. 2014), and miR-155-5p mediates many pro-inflammatory effects of LPS by targeting inhibitors of NF-kB signaling, such as suppressor of cytokine signaling 1 and brain and muscle ARNTL-like 1 (Curtis et al. 2015; Wang et al. 2016). Interestingly, low amounts of LPS continuously leak from the intestine to the blood, enhanced by an HFD, where LPS is inactivated by binding 
to lipoproteins, such as LDL and VLDL. However, chemical modification of LDL leads to reactivation of LPS (Zhu et al. 2017) and upregulation of miR-155-5p in macrophages via toll-like receptor 4 (TLR4) (Du et al. 2014). Accordingly, LPS is detectable in human atherosclerotic lesions, and patients with carotid stenosis have higher blood levels of LPS (Carnevale et al. 2018). Moreover, miR-342-5p, which is abundantly expressed in atherosclerotic lesions, promotes LPS-induced inflammatory macrophage activation by targeting Akt1 and thus upregulates miR-155-5p expression (Wei et al. 2013) (Fig. 4). Blocking miR-342-5p in Apoe ${ }^{-/}$mice reduces atherosclerosis and miR-155-5p expression in atherosclerotic vessels (Wei et al.

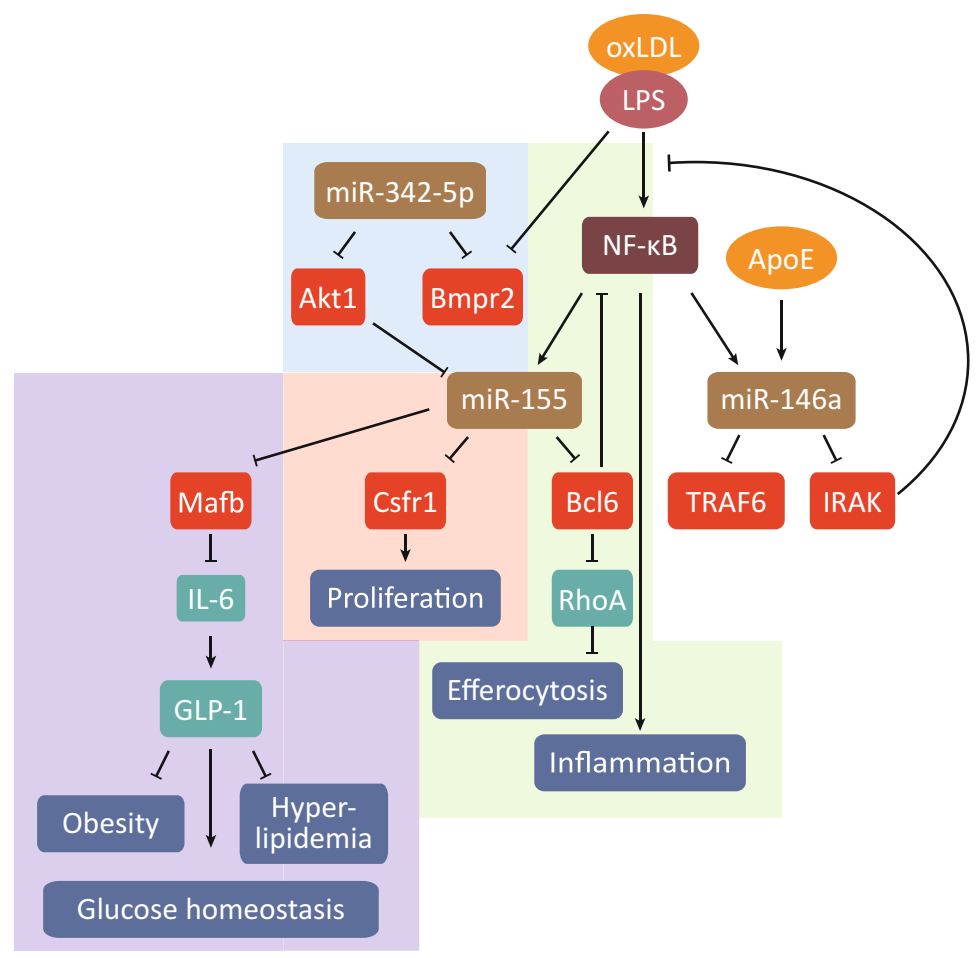

Fig. 4 The complex roles of the LPS mediators miR-155 and miR-146a in atherosclerosis. The stimulation of macrophages with LPS upregulates miR-155 and miR-146a via NF-kB activation. Whereas miR-155 promotes the NF- $\mathrm{KB}$-mediated inflammatory response in macrophages by targeting Bcl6, miR-146a suppresses mediators of LPS signaling and NF- $\mathrm{KB}$ activation. MiR-155 increases advanced atherosclerosis by targeting Bcl6, which drives inflammation and inhibits efferocytosis, thus resulting in necrotic core formation in Apoe $e^{-1}$ mice (green). In early atherosclerosis, however, miR-155 decreases lesion growth by blocking macrophage proliferation (pink). Moreover, miR-155 improves glucose homeostasis and reduces atherosclerosis in obese $\mathrm{Ldlr}^{-1-}$ mice by targeting Mafb in pancreatic $\beta$-cells (violet). The effect of miR-146a in macrophages on atherosclerosis is less clear. Although treatment with miR-146a mimics reduces atherosclerosis and macrophage activation, the anti-inflammatory role of miR-146a in ECs may also protect from lesion formation 
2013). The expression level of miR-342-5p and inflammatory cytokines is increased in peripheral leukocytes from patients with coronary artery disease (Ahmadi et al. 2018). However, the effect of miR-155-5p on macrophages during lesion formations differs considerably between early and advanced lesions (Nazari-Jahantigh et al. 2012; Wei et al. 2015). Whereas miR-155-5p expression in early atherosclerosis limits lesion formation by reducing macrophage proliferation, the formation of advanced lesions is promoted by miR-155-5p through inflammation-induced impairment of efferocytosis (Wei et al. 2015). The latter effect is mediated by the targeting of $B$ cell leukemia/lymphoma 6(BCL6), a transcriptional repressor of NF-KB-induced genes, which improves efferocytosis through inhibition of Ras homolog family member A (RhoA) (Fig. 4) (Wei et al. 2015).

In contrast to its role in Apoe ${ }^{-1-}$ mice, miR-155-5p limits advanced atherosclerosis in $\mathrm{Ldlr}^{-1-}$ mice (Zhu et al. 2017). This effect is due to the upregulation of miR-155-5p in pancreatic $\beta$-cells, which promotes insulin secretion by targeting v-maf musculoaponeurotic fibrosarcoma oncogene family, protein B (MafB). The suppression of MafB by miR-155-5p increases IL-6 secretion from $\beta$-cells, which stimulates glucagon-like peptide (GLP)-1 expression in $\alpha$-cells (Fig. 4). In hyperlipidemic $\mathrm{Ldll}^{-/-}$mice, Mir155 knockout increases obesity, adipose tissue inflammation, blood lipid levels, and blood glucose levels (Zhu et al. 2017). GLP-1 inhibits glucagon production and increases insulin secretion, which may explain how miR-155-5p in $\beta$-cells improves the metabolic status of obese and hyperlipidemic mice. Moreover, miR-155-5p expression increases GLP-1 plasma levels, which may limit vascular inflammation and atherosclerosis (Zhu et al. 2017; Rakipovski et al. 2018). Hyperlipidemia stimulates miR-155-5p expression in $\beta$-cells probably due to HFD-induced endotoxemia because LPS bound to oxidized LDL is deposited in pancreatic islets and oxidation of LDL reactivates LPS (Zhu et al. 2017). Apoe ${ }^{-/-}$mice are more sensitive to the pro-inflammatory effects of LPS than $\mathrm{Ldlr}^{-/-}$mice (Ali et al. 2005). Thus, the pro-atherogenic role of miR-155-5p in macrophages may predominate in Apoe ${ }^{-/-}$mice (Schreyer et al. 2002, 2003), whereas metabolic effects of miR-155-5p related to glucose hemostasis, obesity, and adipose tissue inflammation are more critical for the development of atherosclerosis in $\mathrm{Ldll}^{-1-}$ mice. Thus, hyperlipidemia improves glucose metabolism and adipose tissue inflammation by LPS-mediated upregulation of miR-155-5p in $\beta$-cells. This mechanism may explain why patients with familial hypercholesterolemia have a reduced risk for type 2 diabetes (Besseling et al. 2015).

Besides, exosomes transfer miR-155-5p from hematopoietic cells, such as dendritic cells and neutrophils, and smooth muscle cells to other cell types like ECs (Gomez et al. 2020; Zheng et al. 2017). The uptake of exosomal miR-155-5p sensitizes the recipient cells to LPS-induced inflammatory activation by suppressing its target genes (Alexander et al. 2015). In neutrophils, HFD increases the packaging of miR-155-5p into microvesicles and stimulates their release into the circulation, where they are preferentially taken up by ECs exposed to disturbed blood flow (Gomez et al. 2020). The uptake of the neutrophil-derived microvesicles by ECs promotes their inflammatory activation by miR-155-5p-mediated suppression of BCL6 and increases atherosclerosis (Gomez et al. 2020). Thus, the exosomal 
transfer of miR-155-5p from neutrophils is essential for the pro-atherogenic role of this miRNA in ECs (Gomez et al. 2020) because the endogenous level of miR-155$5 \mathrm{p}$ in ECs is not high enough to drive lesion formation in $A p o e^{-/-}$mice (Wei et al. 2015).

In macrophages, NF- $\kappa \mathrm{B}$ activation by LPS also induces the expression of miR-146a-5p, which antagonizes the pro-inflammatory effects of miR-155-5p by targeting components of the TLR4 signaling pathway, such as interleukin 1 receptor-associated kinase (IRAK) and TNF receptor-associated factor 6 (TRAF6)

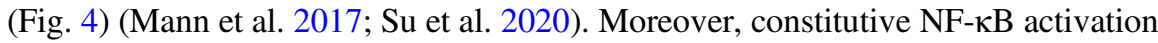
in Mir146a knockout mice drives the development of myeloid malignancies (Zhao et al. 2011). Notably, increased levels of miR-155-5p in macrophages mediate the

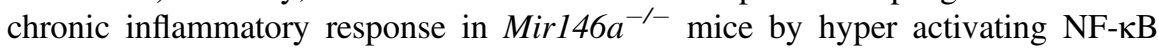
(Mann et al. 2017). Treatment of $L d l r^{-/}$mice with miR-146a mimics reduces atherosclerosis and inflammatory macrophage accumulation (Li et al. 2015). Notably, the anti-inflammatory effects of ApoE are partially mediated by the upregulation of miR-146a ( $\mathrm{Li}$ et al. 2015). However, the atherosclerosis phenotype of HFD-fed Mirl $46 a^{-/-} / \mathrm{Ldlr}^{-/-}$mice, which develop bone marrow failure and splenomegaly, is unexpected. Although Mirl 46a knockout increases inflammatory cytokine levels in the blood, it decreases lipid levels and the progression of advanced atherosclerosis (Cheng et al. 2017b). This effect was due to the lack of miR-146a expression in bone marrow cells, probably because it leads to bone marrow failure and reduced production of pro-atherogenic hematopoietic cells (Cheng et al. 2017b). By contrast, Mirl46a knockout in $\mathrm{Ldlr}^{-1-}$ mice harboring Mirl46a wildtype bone marrow cells develop increased atherosclerotic lesions. These mice are also more sensitive to arterial inflammation, which may be due to increased NF- $\kappa \mathrm{B}$ activation in ECs (Cheng et al. 2013, 2017b). Although another study using the same mouse model also found lower blood lipid levels, it did not detect an effect of Mir146a knockout in bone marrow cells on the development of atherosclerosis (Del Monte et al. 2018).

miR-146b is the second member of the miR-146 seed family and differs from miR-146a in two nucleotides at the $3^{\prime}$ end. Similar to miR-146a, miR-146b inhibits NF- $\kappa \mathrm{B}$ activation and the TLR4 pathway (Taganov et al. 2006). Mir146b knockout mice also develop hematologic malignancies and splenomegaly, although less frequently than Mirl46a $a^{-/-}$mice (Mitsumura et al. 2018). It remains unclear whether miR-146b expression, which is not affected by Mir146a knockout because it is transcribed from a different genomic locus, can compensate for the lack of miR-146a expression. Notably, murine macrophages stimulated with IL-4 release exosomes that contain preferentially miR-146b together with miR-99a and miR-378a (Bouchareychas et al. 2020). The transfer of each of these miRNAs to LPS-stimulated macrophages reduces NF- $\kappa \mathrm{B}$ activation. Moreover, treatment with exosomes from IL-4-treated macrophages reduces inflammation in atherosclerotic lesions but not lesion size (Bouchareychas et al. 2020). 


\subsection{Regulatory RNAs Control Macrophage Death and Efferocytosis in Necrotic Core Formation}

Necrotic core formation results from the disbalance between cell death and efferocytosis. As reported in the previous chapter, miR-155-5p establishes an essential link between inflammatory activation and impaired efferocytosis during the progression of atherosclerosis, which promotes the formation of a necrotic core (Wei et al. 2015). Besides miR-155-5p, miR-21a-5p, one of the most abundant miRNAs in atherosclerotic lesions, has been implicated in necrotic core formation. miR-21 is an oncomiR that inhibits apoptosis by targeting, e.g., programmed cell death protein 4 (Krichevsky and Gabriely 2009; Hatley et al. 2010). Accordingly, knockout of Mir21a in bone marrow cells promotes lesional apoptosis, necrotic core formation, and atherosclerosis in HFD-fed $L d l r^{-/-}$mice, but it reduces lesions in the aortic sinus in Apoe ${ }^{-/-}$mice fed a regular diet (Canfran-Duque et al. 2017; Chipont et al. 2019). Whole-body Mir21a knockout also reduces atherosclerotic lesions, although not in every arterial region studied, in $A p o e^{-/-}$mice fed an HFD and in aged $A p o e^{-/-}$mice fed a regular diet (Chipont et al. 2019; Gao et al. 2019b). Chipont et al. reported the conflicting finding that the inhibition of lesion formation by Mir2la knockout is associated with increased apoptosis of lesional macrophages and impaired efferocytosis in the peritoneum (Chipont et al. 2019). Another puzzling finding in this regard is that Jin et al. described increased lesion size by Mir2la knockout in $A p o e^{-/-}$mice fed a regular diet (Jin et al. 2018). Unfortunately, the mechanisms of these Mir2la effects are incompletely understood.

As discussed in the section "Regulatory RNAs in macrophage energy and lipid metabolism," HIF- $1 \alpha$ activation in macrophages drives necrotic core formation in part by inducing miR-210, which inhibits OXPHOS and promotes necroptosis. Besides, HIF-1 $\alpha$ activation lowers ATP levels in macrophages by suppressing miR-383-5p expression (Karshovska et al. 2020). miR-383-5p limits ATP consumption by targeting poly(ADP-ribose) glycohydrolase (PARG) (Karshovska et al. 2020), which removes poly(ADP-)ribose polymers from DNA strand breaks and thus antagonizes the ATP-dependent role of poly(ADP-ribose) polymerase (PARP)1 in response to RNS-induced DNA damage (Ying et al. 2001). The increased activity of PARG following HIF-1 $\alpha$-mediated suppression of miR-383-5p leads to hyperactivation of PARP-1, and thus to ATP depletion and RIP3-mediated necroptosis (Karshovska et al. 2020). Blocking the interaction between miR-383$5 \mathrm{p}$ and PARG in mice reversed the protective effect of Hifla knockout in myeloid cells on the lesion and necrotic core formation, demonstrating the critical role of miR-383-5p in HIF-1 $\alpha$-mediated lesional macrophage necroptosis (Karshovska et al. 2020).

A genome-wide screen for SNPs associated with myocardial infarction discovered the lncRNA MIAT. Six SNPs in the MIAT gene are strongly associated with myocardial infarction, indicating that they contribute to the genetic risk of cardiovascular disease (Ishii et al. 2006). MIAT expression is upregulated in atherosclerotic lesions, and adenoviral knockdown of MIAT in Apoe $e^{-1-}$ mice reduced advanced atherosclerosis, necrotic core formation, and efferocytosis (Ye et al. 
2019). Notably, MIAT impairs the phagocytic activity of macrophages by binding to miR-149-5p in the RISC, thus upregulating the anti-phagocytic receptor CD47, a target of miR-149-5p (Ye et al. 2019; Kojima et al. 2016).

\section{$4 \quad$ MALAT1: The Master miRNA Sponge}

The evolutionary conserved lncRNA MALAT1 (Johnsson et al. 2014) is transcribed from a single exon into a 7-kb long RNA molecule, which adopts a complex secondary structure, including a triple helix and a t-RNA-like cloverleaf at the $3^{\prime}$ end (McCown et al. 2019). The triple helix structure is conserved and increases the stability of the poly(A) tail-lacking MALAT1 lncRNA. Cleavage by RNase P releases the cloverleaf structure from the $3^{\prime}$ end, which is called Malat1-associated small cytoplasmic RNA (mascRNA). In contrast to the processed MALAT1, which is predominantly retained in the nuclear speckles, mascRNA is transferred into the cytoplasm.

The term "miRNA sponge" fits no other lncRNA better than to MALAT1, which contains an extensively high number of canonical miRNA binding sites (Plotnikova et al. 2019). Several studies have shown that MALAT1 is associated with Ago2 in the RISC, where miRNAs, such as miR-22-3p and miR-155-5p, target MALAT1 (Cao et al. 2016; Tang et al. 2015). Surprisingly, the interaction with MALAT1 also reduces the expression of the targeting miRNA (Tang et al. 2015). The functional interaction with more than 50 miRNAs has been established experimentally in various cell types. In ECs, several MALAT1-binding miRNAs have been described, such as miR-19b-3p, miR-216-5p, miR-181b, and miR-155 (Liu et al. 2020; Wang et al. 2019a; Li et al. 2018).

In macrophages, LPS stimulation increases MALAT1 expression in an NF- $\mathrm{BB}-$ dependent manner, whereas IL-4 downregulates MALAT1 (Cui et al. 2019; Zhao et al. 2016). In mice, MALAT1 promotes LPS-induced inflammatory activation of macrophages by upregulating C-type lectin domain family 16, member A, indicating a pro-inflammatory role of MALAT1 (Cui et al. 2019). Moreover, MALAT1 inhibits IL-4-induced anti-inflammatory and pro-fibrotic macrophage polarization by glucose-dependent OXPHOS (Cui et al. 2019). LPS also induces MALAT1 via activating NF- $\mathrm{BB}$ in human THP-1 macrophages. However, in contrast to murine macrophages, MALAT1 reduces inflammatory cytokine expression in THP-1 cells by binding NF- $\kappa \mathrm{B}$ in the nucleus (Zhao et al. 2016).

In patients with atherosclerosis, MALAT1 expression is reduced in lesions (Cremer et al. 2019; Arslan et al. 2017) and increased in the circulation (Wang et al. 2019a; Zhu et al. 2019). By contrast, lesional Malatl expression is upregulated in Apoe $e^{-1-}$ mice (Li et al. 2019). Treatment with an antagomir against Malat1 for 4 weeks reduces lesion size by almost $50 \%$ in $A p o e^{-/-}$mice fed an HFD for 12 weeks (Zhu et al. 2019). This study indicates that Malat1 promotes atherosclerosis in mice. However, the effect of Malatl knockout on atherosclerosis is quite different. Notably, none of the three existing strains of Malat1 ${ }^{-/}$mice has an obvious phenotype (Eissmann et al. 2012; Nakagawa et al. 2012; Zhang et al. 
2012). Unexpectedly, crossing Malatl $\left(\mathrm{LaCZ}^{-/-}\right.$mice, generated by insertion of the LacZ gene into the promoter region of Malat1, with Apoe $e^{-/-}$mice resulted in intrauterine death, whereas Apoe $e^{-/-}$mice heterozygous for Malat1(LacZ) develop normally (Gast et al. 2019). Interestingly, severe atherosclerosis develops in 8-weekold Malat1 $(\text { LacZ) })^{+/} /$Apoe $e^{-/-}$mice even without feeding them an HFD (Gast et al. 2019), which is probably related to the hyperinflammatory state of these mice (Gast et al. 2019). Whether this effect is due to lower mascRNA levels, which promotes inflammatory cytokine expression in THP-1 cells (Gast et al. 2019), remains unclear. By contrast, Malat $^{-1-}$ mice produced by Cre-mediated excision of the whole Malatl gene could be crossed with Apoe $e^{-/-}$mice without having a spontaneous phenotype (Cremer et al. 2019). Moreover, feeding these mice an HFD with only a comparably small amount of cholesterol for 12 weeks did not change lesion size, but slightly increased lesional leukocyte accumulation (Cremer et al. 2019). Besides, Malat1 knockout in bone marrow cells slightly increased lesion size, and the production of inflammatory leukocytes in Apoe $e^{-/-}$after 16 weeks of HFD feeding, probably due to the loss of miR-503-5p sponging by Malatl in macrophages (Cremer et al. 2019; Yan et al. 2017). Unfortunately, it is not clear whether also non-irradiated Malat $^{-/-} /$Apoe $^{-/-}$mice show the same changes in the production of inflammatory leukocytes as irradiated mice. The expression of numerous miRNAs is increased in Malat1(LacZ) $)^{+/} /$Apoe $^{-/-}$mice; however, not that of miR-503-5p (Gast et al. 2019). Taken together, studies in mice with a deletion of the Malat1 gene indicate a protective role of Malat1 in macrophages, although the extent of its effect differs considerably between the models. A significant difference between the two Malat $^{-1-}$ mouse strains consists in the regulation of NEAT1, a lncRNA transcribed from a neighboring gene of MALAT1. In Malat $^{-/-} /$Apoe $^{-/-}$mice, NEAT1 is upregulated in lung tissue (Cremer et al. 2019), whereas Malatl(LacZ) ${ }^{+/-} /$Apoe $^{-/-}$ mice express lower levels of NEAT1 in splenocytes than Malat1 wildtype mice (Gast et al. 2019). NEAT1 enhances oxidized LDL-induced inflammatory activation and foam cell formation in human and mouse macrophage cell lines by the sponging of miRNAs, such as miR-342-3p and miR-128, and by the formation of paraspeckles (Chen et al. 2018; Huang-Fu et al. 2018; Wang et al. 2019b).

\section{The Simian IncRNA ANRIL and the Risk Locus for Atherosclerosis}

The chromosome 9p21.3 in humans represents a risk locus for many different diseases, including atherosclerosis and coronary artery disease (CAD) (Chen et al. 2014). The $58 \mathrm{~kb}$-long $\mathrm{CAD}$ risk region includes 59 single nucleotide polymorphisms and is devoid of protein-coding genes, but encodes the $3^{\prime}$ end of the lncRNA ANRIL. Therefore, changes in one of the various ANRIL transcripts by the risk haplotype have been linked to atherosclerosis (Lo Sardo et al. 2018). During rodent evolution, ANRIL was gradually lost and is absent in mouse and rat (He et al. 2013). However, mice have a syntenic region on chromosome 4 ortholog to the 9p21.3 locus, which encodes a lncRNA that is different from ANRIL (Visel et al. 
2010). Knockout of the murine 9p21.3 ortholog in $A p o e^{-/-}$mice increases atherosclerosis and lesion calcification but not lesion vulnerability (Kojima et al. 2020). Remarkably, the histological changes in mice were matched with those determined in human lesions from patients carrying the 9p21 risk allele, indicating that it promotes atherosclerosis by lesion calcification independent of ANRIL (Kojima et al. 2020).

\section{Conclusions and Therapeutic Perspectives}

The world of regulatory RNAs in atherosclerosis has expanded considerably by the combined effects of miRNAs and lncRNAs. Especially the small number of conserved lncRNAs plays an essential role in regulating miRNA activities in atherosclerosis. However, more details about the mechanisms of miRNA sponging and the mutual regulation of miRNAs and lncRNAs are needed. Besides, the fact that the great majority of IncRNAs is species-specific raises the possibility that the often-claimed lack of transferability of mouse data into humans is, at least partly, related to lncRNAs. Whether the conservation of lncRNAs goes beyond pure sequence similarities and could be related to structural conservation or conservation of the genomic locus is unclear. Besides, we think it is also essential to reconsider the conservation of miRNA functions against this background because it might not always be possible to predict that a miRNA in mice and humans only from the sequence conservation of its binding site.

Beyond the species-specific differences of regulatory RNA functions, the chronic course of atherosclerosis passing through various, considerably different stages, which may all be present in one patient simultaneously, is a significant obstacle for any kind of drug therapy of this disease. Therefore, it is essential to identify the stage(s) of atherosclerosis that is/are most suitable for therapeutic interventions and ideally develop a transient treatment with long-term beneficial effects avoiding continuous drug application. According to the regulatory RNA functions described in this article, miRNAs tightly control two critical processes in the pathogenesis of atherosclerosis, which can be targeted by miRNA-based therapies: endothelial dysadaptation and necrotic core formation. In a preventive approach, miRNAbased drugs could reprogram dysadapted ECs to develop an arterial endothelial phenotype without the correct hemodynamic stimulus. By contrast, limiting necrotic core formation and plaque rupture by miRNA-based drugs would make it necessary to define and identify lesions where cell apoptosis begins to exceed the lesional efferocytosis capacity. Although different strategies of miRNA-based therapies are currently tested (Roberts et al. 2020; Herrera et al. 2018), it remains unclear how promising the application of drugs comprising miRNA duplexes and oligonucleotide-based competitive miRNA inhibitors is. One miRNA, such as miR-155, may have opposing effects in different atherosclerosis stages through distinct targets. Thus, tailored miRNA inhibitors, such as target site blockers, which specifically block the interaction of a miRNA with only one of its targets, maybe an alternative approach to reduce unwanted effects. Moreover, more specific 
targeting of individual miRNA interactions may enhance efficacy and require lower doses of therapeutic oligonucleotides, thus improving safety.

\section{References}

Ahmadi R, Heidarian E, Fadaei R, Moradi N, Malek M, Fallah S (2018) miR-342-5p expression levels in coronary artery disease patients and its association with inflammatory cytokines. Clin Lab 64(4):603-609

Akhtar S, Hartmann P, Karshovska E, Rinderknecht FA, Subramanian P, Gremse F et al (2015) Endothelial hypoxia-inducible factor- $1 \alpha$ promotes atherosclerosis and monocyte recruitment by upregulating microRNA-19a. Hypertension 66(6):1220-1226

Alexander M, Hu R, Runtsch MC, Kagele DA, Mosbruger TL, Tolmachova T et al (2015) Exosome-delivered microRNAs modulate the inflammatory response to endotoxin. Nat Commun 6:7321

Ali K, Middleton M, Pure E, Rader DJ (2005) Apolipoprotein E suppresses the type I inflammatory response in vivo. Circ Res 97(9):922-927

Androulidaki A, Iliopoulos D, Arranz A, Doxaki C, Schworer S, Zacharioudaki V et al (2009) The kinase Akt1 controls macrophage response to lipopolysaccharide by regulating microRNAs. Immunity 31(2):220-231

Arslan S, Berkan O, Lalem T, Ozbilum N, Goksel S, Korkmaz O et al (2017) Long non-coding RNAs in the atherosclerotic plaque. Atherosclerosis 266:176-181

Bartel DP (2018) Metazoan microRNAs. Cell 173(1):20-51

Besseling J, Kastelein JJ, Defesche JC, Hutten BA, Hovingh GK (2015) Association between familial hypercholesterolemia and prevalence of type 2 diabetes mellitus. JAMA 313 (10):1029-1036

Bjorkerud S, Bondjers G (1972) Endothelial integrity and viability in the aorta of the normal rabbit and rat as evaluated with dye exclusion tests and interference contrast microscopy. Atherosclerosis 15(3): 285-300

Blackford AN, Stucki M (2020) How cells respond to DNA breaks in mitosis. Trends Biochem Sci 45(4):321-331

Bouchareychas L, Duong P, Covarrubias S, Alsop E, Phu TA, Chung A et al (2020) Macrophage exosomes resolve atherosclerosis by regulating hematopoiesis and inflammation via microRNA cargo. Cell Rep 32(2):107881

Cameron AM, Castoldi A, Sanin DE, Flachsmann LJ, Field CS, Puleston DJ et al (2019) Inflammatory macrophage dependence on $\mathrm{NAD}(+)$ salvage is a consequence of reactive oxygen species-mediated DNA damage. Nat Immunol 20(4):420-432

Canfran-Duque A, Rotllan N, Zhang X, Fernandez-Fuertes M, Ramirez-Hidalgo C, Araldi E et al (2017) Macrophage deficiency of miR-21 promotes apoptosis, plaque necrosis, and vascular inflammation during atherogenesis. EMBO Mol Med 9(9):1244-1262

Cao S, Wang Y, Li J, Lv M, Niu H, Tian Y (2016) Tumor-suppressive function of long noncoding RNA MALAT1 in glioma cells by suppressing miR-155 expression and activating FBXW7 function. Am J Cancer Res 6(11):2561-2574

Carnevale R, Nocella C, Petrozza V, Cammisotto V, Pacini L, Sorrentino V et al (2018) Localization of lipopolysaccharide from Escherichia Coli into human atherosclerotic plaque. Sci Rep 8 (1):3598

Chae S, Ahn BY, Byun K, Cho YM, Yu MH, Lee B et al (2013) A systems approach for decoding mitochondrial retrograde signaling pathways. Sci Signal 6(264):rs4

Chen YL, Jan KM, Lin HS, Chien S (1997) Relationship between endothelial cell turnover and permeability to horseradish peroxidase. Atherosclerosis 133(1):7-14

Chen HH, Almontashiri NA, Antoine D, Stewart AF (2014) Functional genomics of the 9p21.3 locus for atherosclerosis: clarity or confusion? Curr Cardiol Rep 16(7):502 
Chen Z, Wen L, Martin M, Hsu CY, Fang L, Lin FM et al (2015) Oxidative stress activates endothelial innate immunity via sterol regulatory element binding protein 2 (SREBP2) transactivation of microRNA-92a. Circulation 131(9):805-814

Chen J, Shishkin AA, Zhu X, Kadri S, Maza I, Guttman M et al (2016a) Evolutionary analysis across mammals reveals distinct classes of long non-coding RNAs. Genome Biol 17:19

Chen L, Wang J, Wang B, Yang J, Gong Z, Zhao X et al (2016b) MiR-126 inhibits vascular endothelial cell apoptosis through targeting PI3K/Akt signaling. Ann Hematol 95(3):365-374

Chen H, Li X, Liu S, Gu L, Zhou X (2017) MircroRNA-19a promotes vascular inflammation and foam cell formation by targeting HBP-1 in atherogenesis. Sci Rep 7(1):12089

Chen DD, Hui LL, Zhang XC, Chang Q (2018) NEAT1 contributes to ox-LDL-induced inflammation and oxidative stress in macrophages through inhibiting miR-128. J Cell Biochem 120 (2):2493-2501

Cheng HS, Sivachandran N, Lau A, Boudreau E, Zhao JL, Baltimore D et al (2013) MicroRNA-146 represses endothelial activation by inhibiting pro-inflammatory pathways. EMBO Mol Med 5 (7):949-966

Cheng XW, Wan YF, Zhou Q, Wang Y, Zhu HQ (2017a) MicroRNA126 inhibits endothelial permeability and apoptosis in apolipoprotein E-knockout mice fed a high-fat diet. Mol Med Rep 16(3):3061-3068

Cheng HS, Besla R, Li A, Chen Z, Shikatani EA, Nazari-Jahantigh M et al (2017b) Paradoxical suppression of therosclerosis in the absence of microRNA-146a. Circ Res 121(4):354-367

Chipman LB, Pasquinelli AE (2019) miRNA targeting: growing beyond the seed. Trends Genet 35 (3):215-222

Chipont A, Esposito B, Challier I, Montabord M, Tedgui A, Mallat Z et al (2019) MicroRNA-21 deficiency alters the survival of Ly-6C(lo) monocytes in $\mathrm{ApoE}(-/-)$ mice and reduces earlystage atherosclerosis-brief report. Arterioscler Thromb Vasc Biol 39(2):170-177

Cremer S, Michalik KM, Fischer A, Pfisterer L, Jae N, Winter C et al (2019) Hematopoietic deficiency of the long noncoding RNA MALAT1 promotes atherosclerosis and plaque inflammation. Circulation 139(10):1320-1334

Cui H, Banerjee S, Guo S, Xie N, Ge J, Jiang D et al (2019) Long noncoding RNA Malat1 regulates differential activation of macrophages and response to lung injury. JCI Insight 4(4):e124522

Curtis AM, Fagundes CT, Yang G, Palsson-McDermott EM, Wochal P, McGettrick AF et al (2015) Circadian control of innate immunity in macrophages by miR-155 targeting Bmal1. Proc Natl Acad Sci U S A 112(23):7231-7236

Del Monte A, Arroyo AB, Andres-Manzano MJ, Garcia-Barbera N, Caleprico MS, Vicente V et al (2018) miR-146a deficiency in hematopoietic cells is not involved in the development of atherosclerosis. PLoS One 13(6):e0198932

Döring Y, Noels H, van der Vorst EPC, Neideck C, Egea V, Drechsler M et al (2017) Vascular CXCR4 limits atherosclerosis by maintaining arterial integrity: evidence from mouse and human studies. Circulation 136(4):388-403

Doring Y, van der Vorst EPC, Duchene J, Jansen Y, Gencer S, Bidzhekov K et al (2019) CXCL12 derived from endothelial cells promotes atherosclerosis to drive coronary artery disease. Circulation 139(10):1338-1340

Du F, Yu F, Wang Y, Hui Y, Carnevale K, Fu M et al (2014) MicroRNA-155 deficiency results in decreased macrophage inflammation and attenuated atherogenesis in apolipoprotein E-deficient mice. Arterioscler Thromb Vasc Biol 34(4):759-767

Dueck A, Eichner A, Sixt M, Meister G (2014) A miR-155-dependent microRNA hierarchy in dendritic cell maturation and macrophage activation. FEBS Lett 588(4):632-640

Ebert MS, Sharp PA (2012) Roles for MicroRNAs in conferring robustness to biological processes. Cell 149(3):515-524

Eissmann M, Gutschner T, Hammerle M, Gunther S, Caudron-Herger M, Gross M et al (2012) Loss of the abundant nuclear non-coding RNA MALAT1 is compatible with life and development. RNA Biol 9(8):1076-1087 
Fang Y, Davies PF (2012) Site-specific microRNA-92a regulation of Kruppel-like factors 4 and 2 in atherosusceptible endothelium. Arterioscler Thromb Vasc Biol 32(4):979-987

Finnerty JR, Wang WX, Hebert SS, Wilfred BR, Mao G, Nelson PT (2010) The miR-15/107 group of microRNA genes: evolutionary biology, cellular functions, and roles in human diseases. J Mol Biol 402(3):491-509

Fish JE, Santoro MM, Morton SU, Yu S, Yeh RF, Wythe JD et al (2008) miR-126 regulates angiogenic signaling and vascular integrity. Dev Cell 15(2):272-284

Fromm B, Billipp T, Peck LE, Johansen M, Tarver JE, King BL et al (2015) A uniform system for the annotation of vertebrate microRNA genes and the evolution of the human microRNAome. Annu Rev Genet 49:213-242

Gantier MP, McCoy CE, Rusinova I, Saulep D, Wang D, Xu D et al (2011) Analysis of microRNA turnover in mammalian cells following Dicer1 ablation. Nucleic Acids Res 39(13):5692-5703

Gao JH, He LH, Yu XH, Zhao ZW, Wang G, Zou J et al (2019a) CXCL12 promotes atherosclerosis by downregulating ABCA1 expression via the CXCR4/GSK3beta/beta-catenin(T120)/TCF21 pathway. J Lipid Res 60(12):2020-2033

Gao L, Zeng H, Zhang T, Mao C, Wang Y, Han Z et al (2019b) MicroRNA-21 deficiency attenuated atherogenesis and decreased macrophage infiltration by targeting Dusp-8. Atherosclerosis 291:78-86

Gast M, Rauch BH, Nakagawa S, Haghikia A, Jasina A, Haas J et al (2019) Immune systemmediated atherosclerosis caused by deficiency of long non-coding RNA MALAT1 in ApoE-/mice. Cardiovasc Res 115(2):302-314

Gau GS, Ryder TA, Mackenzie ML (1980) The effect of blood flow on the surface morphology of the human endothelium. J Pathol 131(1):55-64

Gerrity RG, Richardson M, Somer JB, Bell FP, Schwartz CJ (1977) Endothelial cell morphology in areas of in vivo Evans blue uptake in the aorta of young pigs. II. Ultrastructure of the intima in areas of differing permeability to proteins. Am J Pathol 89(2):313-334

Gomez I, Ward B, Souilhol C, Recarti C, Ariaans M, Johnston J et al (2020) Neutrophil microvesicles drive atherosclerosis by delivering miR-155 to atheroprone endothelium. Nat Commun 11(1):214

Hansson GK, Chao S, Schwartz SM, Reidy MA (1985) Aortic endothelial cell death and replication in normal and lipopolysaccharide-treated rats. Am J Pathol 121(1):123-127

Hartmann P, Zhou Z, Natarelli L, Wei Y, Nazari-Jahantigh M, Zhu M et al (2016) Endothelial dicer promotes atherosclerosis and vascular inflammation by miRNA-103-mediated suppression of KLF4. Nat Commun 7:10521

Hatley ME, Patrick DM, Garcia MR, Richardson JA, Bassel-Duby R, van Rooij E et al (2010) Modulation of K-Ras-dependent lung tumorigenesis by MicroRNA-21. Cancer Cell 18 (3):282-293

He S, Liang Y, Shao F, Wang X (2011) Toll-like receptors activate programmed necrosis in macrophages through a receptor-interacting kinase-3-mediated pathway. Proc Natl Acad Sci U S A 108(50):20054-20059

He S, Gu W, Li Y, Zhu H (2013) ANRIL/CDKN2B-AS shows two-stage clade-specific evolution and becomes conserved after transposon insertions in simians. BMC Evol Biol 13(1):247

Hennessy EJ, van Solingen C, Scacalossi KR, Ouimet M, Afonso MS, Prins J et al (2019) The long noncoding RNA CHROME regulates cholesterol homeostasis in primate. Nat Metab 1 (1):98-110

Heo KS, Lee H, Nigro P, Thomas T, Le NT, Chang E et al (2011) PKCzeta mediates disturbed flowinduced endothelial apoptosis via p53 SUMOylation. J Cell Biol 193(5):867-884

Heo KS, Chang E, Le NT, Cushman H, Yeh ET, Fujiwara K et al (2013) De-SUMOylation enzyme of sentrin/SUMO-specific protease 2 regulates disturbed flow-induced SUMOylation of ERK5 and p53 that leads to endothelial dysfunction and atherosclerosis. Circ Res 112(6):911-923

Herrera VL, Colby AH, Ruiz-Opazo N, Coleman DG, Grinstaff MW (2018) Nucleic acid nanomedicines in phase II/III clinical trials: translation of nucleic acid therapies for reprogramming cells. Nanomedicine (Lond) 13(16):2083-2098 
Horie T, Baba O, Kuwabara Y, Chujo Y, Watanabe S, Kinoshita M et al (2012) MicroRNA-33 deficiency reduces the progression of atherosclerotic plaque in ApoE-/- mice. J Am Heart Assoc 1(6): 0003376

Huang R, Hu Z, Cao Y, Li H, Zhang H, Su W et al (2019) MiR-652-3p inhibition enhances endothelial repair and reduces atherosclerosis by promoting cyclin D2 expression. EBioMedicine 40:685-694

Huang-Fu N, Cheng JS, Wang Y, Li ZW, Wang SH (2018) Neat1 regulates oxidized low-density lipoprotein-induced inflammation and lipid uptake in macrophages via paraspeckle formation. Mol Med Rep 17(2):3092-3098

Ishii N, Ozaki K, Sato H, Mizuno H, Saito S, Takahashi A et al (2006) Identification of a novel non-coding RNA, MIAT, that confers risk of myocardial infarction. J Hum Genet 51 (12):1087-1099

Jiang L, Qiao Y, Wang Z, Ma X, Wang H, Li J (2020) Inhibition of microRNA-103 attenuates inflammation and endoplasmic reticulum stress in atherosclerosis through disrupting the PTENmediated MAPK signaling. J Cell Physiol 235(1):380-393

Jin H, Li DY, Chernogubova E, Sun C, Busch A, Eken SM et al (2018) Local delivery of miR-21 stabilizes fibrous caps in vulnerable atherosclerotic lesions. Mol Ther 26(4):1040-1055

Johnsson P, Lipovich L, Grander D, Morris KV (2014) Evolutionary conservation of long non-coding RNAs; sequence, structure, function. Biochim Biophys Acta 1840(3):1063-1071

Karshovska E, Wei Y, Subramanian P, Mohibullah R, Geissler C, Baatsch I et al (2020) HIF-1alpha (Hypoxia-inducible factor-1alpha) promotes macrophage necroptosis by regulating miR-210 and miR-383. Arterioscler Thromb Vasc Biol 40(3):583-596

Kim S, Woo CH (2018) Laminar flow inhibits ER stress-induced endothelial apoptosis through PI3K/Akt-dependent signaling pathway. Mol Cells 41(11):964-970

Kiraly O, Gong G, Olipitz W, Muthupalani S, Engelward BP (2015) Inflammation-induced cell proliferation potentiates DNA damage-induced mutations in vivo. PLoS Genet 11(2):e1004901

Kojima Y, Volkmer JP, McKenna K, Civelek M, Lusis AJ, Miller CL et al (2016) CD47-blocking antibodies restore phagocytosis and prevent atherosclerosis. Nature 536(7614):86-90

Kojima Y, Ye J, Nanda V, Wang Y, Flores AM, Jarr KU et al (2020) Knockout of the murine ortholog to the human 9p21 coronary artery disease locus leads to smooth muscle cell proliferation, vascular calcification, and advanced atherosclerosis. Circulation 141(15):1274-1276

Kopp F, Mendell JT (2018) Functional classification and experimental dissection of long noncoding RNAs. Cell 172(3):393-407

Kosik KS (2010) MicroRNAs and cellular phenotypy. Cell 143(1):21-26

Krichevsky AM, Gabriely G (2009) miR-21: a small multi-faceted RNA. J Cell Mol Med 13 (1):39-53

Kuhnert F, Mancuso MR, Hampton J, Stankunas K, Asano T, Chen CZ et al (2008) Attribution of vascular phenotypes of the murine Egfl7 locus to the microRNA miR-126. Development 135 (24):3989-3993

Lee H, Han S, Kwon CS, Lee D (2015) Biogenesis and regulation of the let-7 miRNAs and their functional implications. Protein Cell 7(2):100-113

Lee DY, Yang TL, Huang YH, Lee CI, Chen LJ, Shih YT et al (2018) Induction of microRNA-10a using retinoic acid receptor-alpha and retinoid $\mathrm{x}$ receptor-alpha agonists inhibits atherosclerotic lesion formation. Atherosclerosis 271:36-44

Li K, Ching D, Luk FS, Raffai RL (2015) Apolipoprotein E enhances microRNA-146a in monocytes and macrophages to suppress nuclear factor-kappaB-driven inflammation and atherosclerosis. Circ Res 117(1):e1-e11

Li XX, Liu YM, Li YJ, Xie N, Yan YF, Chi YL et al (2016) High glucose concentration induces endothelial cell proliferation by regulating cyclin-D2-related miR-98. J Cell Mol Med 20 (6):1159-1169

Li S, Sun Y, Zhong L, Xiao Z, Yang M, Chen M et al (2018) The suppression of ox-LDL-induced inflammatory cytokine release and apoptosis of HCAECs by long non-coding RNA-MALAT1 via regulating microRNA-155/SOCS1 pathway. Nutr Metab Cardiovasc Dis 28(11):1175-1187 
Li H, Zhao Q, Chang L, Wei C, Bei H, Yin Y et al (2019) LncRNA MALAT1 modulates ox-LDL induced EndMT through the Wnt/beta-catenin signaling pathway. Lipids Health Dis 18(1):62

Liang B, Wang X, Song X, Bai R, Yang H, Yang Z et al (2017) MicroRNA-20a/b regulates cholesterol efflux through post-transcriptional repression of ATP-binding cassette transporter A1. Biochim Biophys Acta Mol Cell Biol Lipids 1862(9):929-938

Lin J, Li H, Yang M, Ren J, Huang Z, Han F et al (2013) A role of RIP3-mediated macrophage necrosis in atherosclerosis development. Cell Rep 3(1):200-210

Liu Y, Li Q, Hosen MR, Zietzer A, Flender A, Levermann P et al (2019) Atherosclerotic conditions promote the packaging of functional microRNA-92a-3p into endothelial microvesicles. Circ Res 124(4):575-587

Liu H, Shi C, Deng Y (2020) MALAT1 affects hypoxia-induced vascular endothelial cell injury and autophagy by regulating miR-19b-3p/HIF-1alpha axis. Mol Cell Biochem 466(1-2):25-34

Lo Sardo V, Chubukov P, Ferguson W, Kumar A, Teng EL, Duran M et al (2018) Unveiling the role of the most impactful cardiovascular risk locus through haplotype editing. Cell 175 (7): 1796-810.e20

Loyer X, Potteaux S, Vion AC, Guerin CL, Boulkroun S, Rautou PE et al (2014) Inhibition of microRNA-92a prevents endothelial dysfunction and atherosclerosis in mice. Circ Res 114 (3):434-443

Lv YC, Tang YY, Peng J, Zhao GJ, Yang J, Yao F et al (2014) MicroRNA-19b promotes macrophage cholesterol accumulation and aortic atherosclerosis by targeting ATP-binding cassette transporter A1. Atherosclerosis 236(1):215-226

Mack JJ, Mosqueiro TS, Archer BJ, Jones WM, Sunshine H, Faas GC et al (2017) NOTCH1 is a mechanosensor in adult arteries. Nat Commun 8(1):1620

Mann M, Mehta A, Zhao JL, Lee K, Marinov GK, Garcia-Flores Y et al (2017) An NF-kappaBmicroRNA regulatory network tunes macrophage inflammatory responses. Nat Commun 8 (1):851

McCall MN, Kent OA, Yu J, Fox-Talbot K, Zaiman AL, Halushka MK (2011) MicroRNA profiling of diverse endothelial cell types. BMC Med Genet 4:78

McCown PJ, Wang MC, Jaeger L, Brown JA (2019) Secondary structural model of human MALAT1 reveals multiple structure-function relationships. Int J Mol Sci 20(22):5610

Meiler S, Baumer Y, Toulmin E, Seng K, Boisvert WA (2015) MicroRNA 302a is a novel modulator of cholesterol homeostasis and atherosclerosis. Arterioscler Thromb Vasc Biol 35 (2):323-331

Miinalainen IJ, Schmitz W, Huotari A, Autio KJ, Soininen R, Ver Loren van Themaat E et al (2009) Mitochondrial 2,4-dienoyl-CoA reductase deficiency in mice results in severe hypoglycemia with stress intolerance and unimpaired ketogenesis. PLoS Genet 5(7):e1000543

Mitsumura T, Ito Y, Chiba T, Matsushima T, Kurimoto R, Tanaka Y et al (2018) Ablation of miR-146b in mice causes hematopoietic malignancy. Blood Adv 2(23):3483-3491

Mogilyansky E, Rigoutsos I (2013) The miR-17/92 cluster: a comprehensive update on its genomics, genetics, functions and increasingly important and numerous roles in health and disease. Cell Death Differ 20(12):1603-1614

Mohamied Y, Rowland EM, Bailey EL, Sherwin SJ, Schwartz MA, Weinberg PD (2015) Change of direction in the biomechanics of atherosclerosis. Ann Biomed Eng 43(1):16-25

Mohamied Y, Sherwin SJ, Weinberg PD (2017) Understanding the fluid mechanics behind transverse wall shear stress. J Biomech 50:102-109

Mundi S, Massaro M, Scoditti E, Carluccio MA, van Hinsbergh VWM, Iruela-Arispe ML et al (2018) Endothelial permeability, LDL deposition, and cardiovascular risk factors-a review. Cardiovasc Res 114(1):35-52

Nakagawa S, Ip JY, Shioi G, Tripathi V, Zong X, Hirose T et al (2012) Malat1 is not an essential component of nuclear speckles in mice. RNA 18(8):1487-1499

Natarelli L, Geissler C, Csaba G, Wei Y, Zhu M, di Francesco A et al (2018) miR-103 promotes endothelial maladaptation by targeting lncWDR59. Nat Commun 9(1):2645 
Nazari-Jahantigh M, Wei Y, Noels H, Akhtar S, Zhou Z, Koenen RR et al (2012) MicroRNA-155 promotes atherosclerosis by repressing Bcl6 in macrophages. J Clin Investig 122 (11):4190-4202

Pajuelo D, Gonzalez-Juarbe N, Tak U, Sun J, Orihuela CJ, Niederweis M (2018) NAD(+) depletion triggers macrophage necroptosis, a cell death pathway exploited by Mycobacterium tuberculosis. Cell Rep 24(2):429-440

Pan L, Hong Z, Yu L, Gao Y, Zhang R, Feng H et al (2017) Shear stress induces human aortic endothelial cell apoptosis via interleukin-1 receptor-associated kinase 2-induced endoplasmic reticulum stress. Mol Med Rep 16(5):7205-7212

Patrick DM, Montgomery RL, Qi X, Obad S, Kauppinen S, Hill JA et al (2010) Stress-dependent cardiac remodeling occurs in the absence of microRNA-21 in mice. J Clin Investig 120 (11):3912-3916

Peiffer V, Sherwin SJ, Weinberg PD (2013) Computation in the rabbit aorta of a new metric - the transverse wall shear stress - to quantify the multidirectional character of disturbed blood flow. $\mathrm{J}$ Biomech 46(15):2651-2658

Plotnikova O, Baranova A, Skoblov M (2019) Comprehensive analysis of human microRNAmRNA interactome. Front Genet 10:933

Price NL, Rotllan N, Canfran-Duque A, Zhang X, Pati P, Arias N et al (2017) Genetic dissection of the impact of miR-33a and miR-33b during the progression of atherosclerosis. Cell Rep 21 (5):1317-1330

Price NL, Rotllan N, Zhang X, Canfran-Duque A, Nottoli T, Suarez Y et al (2019) Specific disruption of Abcal targeting largely mimics the effects of miR-33 knockout on macrophage cholesterol efflux and atherosclerotic plaque development. Circ Res 124(6):874-880

Raitoharju E, Lyytikainen LP, Levula M, Oksala N, Mennander A, Tarkka M et al (2011) miR-21, miR-210, miR-34a, and miR-146a/b are up-regulated in human atherosclerotic plaques in the Tampere vascular study. Atherosclerosis 219(1):211-217

Rakipovski G, Rolin B, Nøhr J, Klewe I, Frederiksen KS, Augustin R et al (2018) The GLP-1 analogs liraglutide and semaglutide reduce atherosclerosis in $\mathrm{ApoE}(-/-)$ and $\operatorname{LDLr}(-/-)$ mice by a mechanism that includes inflammatory pathways. JACC Basic Transl Sci 3(6):844-857

Rayner KJ, Suarez Y, Davalos A, Parathath S, Fitzgerald ML, Tamehiro N et al (2010) MiR-33 contributes to the regulation of cholesterol homeostasis. Science 328(5985):1570-1573

Roberts TC, Langer R, Wood MJA (2020) Advances in oligonucleotide drug delivery. Nat Rev Drug Discov 19(10):673-694

Roush S, Slack FJ (2008) The let-7 family of microRNAs. Trends Cell Biol 18(10):505-516

Sallam T, Jones M, Thomas BJ, Wu X, Gilliland T, Qian K et al (2018) Transcriptional regulation of macrophage cholesterol efflux and atherogenesis by a long noncoding RNA. Nat Med 24 (3):304-312

Salvayre R, Auge N, Benoist H, Negre-Salvayre A (2002) Oxidized low-density lipoproteininduced apoptosis. Biochim Biophys Acta 1585(2-3):213-221

Santovito D, Egea V, Bidzhekov K, Natarelli L, Mourão A, Blanchet X et al (2020) Noncanonical inhibition of caspase- 3 by a nuclear microRNA confers endothelial protection by autophagy in atherosclerosis. Sci Transl Med 12(546):eaaz2294

Schober A, Weber C (2016) Mechanisms of microRNAs in atherosclerosis. Annu Rev Pathol 11:583-616

Schober A, Nazari-Jahantigh M, Wei Y, Bidzhekov K, Gremse F, Grommes J et al (2014) MicroRNA-126-5p promotes endothelial proliferation and limits atherosclerosis by suppressing Dlk1. Nat Med 20(4):368-376

Schober A, Nazari-Jahantigh M, Weber C (2015) MicroRNA-mediated mechanisms of the cellular stress response in atherosclerosis. Nat Rev Cardiol 12(6):361-374

Schreyer SA, Vick C, Lystig TC, Mystkowski P, LeBoeuf RC (2002) LDL receptor but not apolipoprotein E deficiency increases diet-induced obesity and diabetes in mice. Am J Physiol Endocrinol Metab 282(1):E207-E214 
Schreyer SA, Lystig TC, Vick CM, LeBoeuf RC (2003) Mice deficient in apolipoprotein E but not LDL receptors are resistant to accelerated atherosclerosis associated with obesity. Atherosclerosis 171(1):49-55

Semo J, Chernin G, Jonas M, Shimoni S, George J (2019) Deletion of the Mir-106b 25 MicroRNA cluster attenuates atherosclerosis in apolipoprotein E knockout mice. Lipids Health Dis 18 (1):208

Shah AV, Bennett MR (2017) DNA damage-dependent mechanisms of ageing and disease in the macro- and microvasculature. Eur J Pharmacol 816:116-128

Siciliano V, Garzilli I, Fracassi C, Criscuolo S, Ventre S, di Bernardo D (2013) MiRNAs confer phenotypic robustness to gene networks by suppressing biological noise. Nat Commun 4:2364

Su YL, Wang X, Mann M, Adamus TP, Wang D, Moreira DF et al (2020) Myeloid cell-targeted miR-146a mimic inhibits NF-kappaB-driven inflammation and leukemia progression in vivo. Blood 135(3):167-180

Suarez Y, Fernandez-Hernando C, Pober JS, Sessa WC (2007) Dicer dependent microRNAs regulate gene expression and functions in human endothelial cells. Circ Res 100(8):1164-1173

Suarez Y, Fernandez-Hernando C, Yu J, Gerber SA, Harrison KD, Pober JS et al (2008) Dicerdependent endothelial microRNAs are necessary for postnatal angiogenesis. Proc Natl Acad Sci U S A 105(37):14082-14087

Taganov KD, Boldin MP, Chang KJ, Baltimore D (2006) NF-kappaB-dependent induction of microRNA miR-146, an inhibitor targeted to signaling proteins of innate immune responses. Proc Natl Acad Sci U S A 103(33):12481-12486

Tan L, Liu L, Jiang Z, Hao X (2019) Inhibition of microRNA-17-5p reduces the inflammation and lipid accumulation, and up-regulates ATP-binding cassette transporterA1 in atherosclerosis. J Pharmacol Sci 139(4):280-288

Tang Y, Jin X, Xiang Y, Chen Y, Shen CX, Zhang YC et al (2015) The IncRNA MALAT1 protects the endothelium against ox-LDL-induced dysfunction via upregulating the expression of the miR-22-3p target genes CXCR2 and AKT. FEBS Lett 589(20 Pt B):3189-3196

Thompson RC, Vardinogiannis I, Gilmore TD (2013) Identification of an NF-kappaB p50/p65-responsive site in the human MIR155HG promoter. BMC Mol Biol 14:24

Thum T, Borlak J (2008) LOX-1 receptor blockade abrogates oxLDL-induced oxidative DNA damage and prevents activation of the transcriptional repressor Oct-1 in human coronary arterial endothelium. J Biol Chem 283(28):19456-19464

Tsao PS, Lewis NP, Alpert S, Cooke JP (1995) Exposure to shear stress alters endothelial adhesiveness. Role of nitric oxide. Circulation 92(12):3513-3519

Tzima E, Irani-Tehrani M, Kiosses WB, Dejana E, Schultz DA, Engelhardt B et al (2005) A mechanosensory complex that mediates the endothelial cell response to fluid shear stress. Nature 437(7057):426-431

Ulitsky I (2016) Evolution to the rescue: using comparative genomics to understand long non-coding RNAs. Nat Rev Genet 17(10):601-614

Uszczynska-Ratajczak B, Lagarde J, Frankish A, Guigo R, Johnson R (2018) Towards a complete map of the human long non-coding RNA transcriptome. Nat Rev Genet 19(9):535-548

van Hinsbergh VW, Scheffer M, Havekes L, Kempen HJ (1986) Role of endothelial cells and their products in the modification of low-density lipoproteins. Biochim Biophys Acta 878(1):49-64

Visel A, Zhu Y, May D, Afzal V, Gong E, Attanasio C et al (2010) Targeted deletion of the 9p21 non-coding coronary artery disease risk interval in mice. Nature 464(7287):409-412

Voellenkle C, Rooij J, Guffanti A, Brini E, Fasanaro P, Isaia E et al (2012) Deep-sequencing of endothelial cells exposed to hypoxia reveals the complexity of known and novel microRNAs. RNA 18(3):472-484

Wang W, Liu Z, Su J, Chen WS, Wang XW, Bai SX et al (2016) Macrophage micro-RNA-155 promotes lipopolysaccharide-induced acute lung injury in mice and rats. Am J Physiol Lung Cell Mol Physiol 311(2):L494-L506 
Wang Y-C, Lee A-S, Lu L-S, Ke L-Y, Chen W-Y, Dong J-W et al (2018) Human electronegative LDL induces mitochondrial dysfunction and premature senescence of vascular cells in vivo. Aging Cell 17(4):e12792-e

Wang K, Yang C, Shi J, Gao T (2019a) Ox-LDL-induced lncRNA MALAT1 promotes autophagy in human umbilical vein endothelial cells by sponging miR-216a-5p and regulating Beclin-1 expression. Eur J Pharmacol 858:172338

Wang L, Xia JW, Ke ZP, Zhang BH (2019b) Blockade of NEAT1 represses inflammation response and lipid uptake via modulating miR-342-3p in human macrophages THP-1 cells. J Cell Physiol 234(4):5319-5326

Wechezak AR, Viggers RF, Coan DE, Sauvage LR (1994) Mitosis and cytokinesis in subconfluent endothelial cells exposed to increasing levels of shear stress. J Cell Physiol 159(1):83-91

Wei Y, Schober A (2016) MicroRNA regulation of macrophages in human pathologies. Cell Mol Life Sci 73(18):3473-3495

Wei Y, Nazari-Jahantigh M, Chan L, Zhu M, Heyll K, Corbalan-Campos J et al (2013) The microRNA-342-5p fosters inflammatory macrophage activation through an Akt1- and microRNA-155-dependent pathway during atherosclerosis. Circulation 127(15):1609-1619

Wei Y, Zhu M, Corbalan-Campos J, Heyll K, Weber C, Schober A (2015) Regulation of Csf1r and Bc16 in macrophages mediates the stage-specific effects of microRNA-155 on atherosclerosis. Arterioscler Thromb Vasc Biol 35(4):796-803

Wei Y, Corbalan-Campos J, Gurung R, Natarelli L, Zhu M, Exner N et al (2018) Dicer in macrophages prevents atherosclerosis by promoting mitochondrial oxidative metabolism. Circulation 138(18):2007-2020

Wiese CB, Zhong J, Xu ZQ, Zhang Y, Ramirez Solano MA, Zhu W et al (2019) Dual inhibition of endothelial miR-92a-3p and miR-489-3p reduces renal injury-associated atherosclerosis. Atherosclerosis 282:121-131

Wu W, Xiao H, Laguna-Fernandez A, Villarreal G Jr, Wang KC, Geary GG et al (2011) Flowdependent regulation of kruppel-like factor 2 is mediated by MicroRNA-92a. Circulation 124 (5):633-641

Wu R, Tang S, Wang M, Xu X, Yao C, Wang S (2016) MicroRNA-497 induces apoptosis and suppresses proliferation via the Bcl-2/Bax-Caspase9-Caspase3 pathway and cyclin D2 protein in HUVECs. PLoS One 11(12):e0167052

Wu H, Yang L, Chen L-L (2017) The diversity of long noncoding RNAs and their generation. Trends Genet 33(8):540-552

$\mathrm{Xu}$ Y, Xu Y, Zhu Y, Sun H, Juguilon C, Li F et al (2020) Macrophage miR-34a is a key regulator of cholesterol efflux and atherosclerosis. Mol Ther 28(1):202-216

Yan W, Wu Q, Yao W, Li Y, Liu Y, Yuan J et al (2017) MiR-503 modulates epithelialmesenchymal transition in silica-induced pulmonary fibrosis by targeting PI3K p85 and is sponged by lncRNA MALAT1. Sci Rep 7(1):11313

Yang S, Ye ZM, Chen S, Luo XY, Chen SL, Mao L et al (2018) MicroRNA-23a-5p promotes atherosclerotic plaque progression and vulnerability by repressing ATP-binding cassette transporter A1/G1 in macrophages. J Mol Cell Cardiol 123:139-149

Yao RW, Wang Y, Chen LL (2019) Cellular functions of long noncoding RNAs. Nat Cell Biol 21 (5):542-551

Ye ZM, Yang S, Xia YP, Hu RT, Chen S, Li BW et al (2019) LncRNA MIAT sponges miR-149-5p to inhibit efferocytosis in advanced atherosclerosis through CD47 upregulation. Cell Death Dis 10(2): 138

Ying W, Sevigny MB, Chen Y, Swanson RA (2001) Poly(ADP-ribose) glycohydrolase mediates oxidative and excitotoxic neuronal death. Proc Natl Acad Sci U S A 98(21):12227-12232

Zannis VI, Chroni A, Krieger M (2006) Role of apoA-I, ABCA1, LCAT, and SR-BI in the biogenesis of HDL. J Mol Med (Berl) 84(4):276-294

Zeng L, Zampetaki A, Margariti A, Pepe AE, Alam S, Martin D et al (2009) Sustained activation of XBP1 splicing leads to endothelial apoptosis and atherosclerosis development in response to disturbed flow. Proc Natl Acad Sci U S A 106(20):8326-8331 
Zernecke A, Bidzhekov K, Noels H, Shagdarsuren E, Gan L, Denecke B et al (2009) Delivery of microRNA-126 by apoptotic bodies induces CXCL12-dependent vascular protection. Sci Signal 2(100):ra81

Zhang B, Arun G, Mao YS, Lazar Z, Hung G, Bhattacharjee G et al (2012) The lncRNA Malat1 is dispensable for mouse development but its transcription plays a cis-regulatory role in the adult. Cell Rep 2(1):111-123

Zhang CZ, Spektor A, Cornils H, Francis JM, Jackson EK, Liu S et al (2015) Chromothripsis from DNA damage in micronuclei. Nature 522(7555):179-184

Zhao JL, Rao DS, Boldin MP, Taganov KD, O'Connell RM, Baltimore D (2011) NF-\{kappa\}B dysregulation in microRNA-146a-deficient mice drives the development of myeloid malignancies. Proc Natl Acad Sci U S A 108(22):9184-9189

Zhao G, Su Z, Song D, Mao Y, Mao X (2016) The long noncoding RNA MALAT1 regulates the lipopolysaccharide-induced inflammatory response through its interaction with NF-kappaB. FEBS Lett 590(17):2884-2895

Zheng B, Yin WN, Suzuki T, Zhang XH, Zhang Y, Song LL et al (2017) Exosome-mediated miR-155 transfer from smooth muscle cells to endothelial cells induces endothelial injury and promotes atherosclerosis. Mol Ther 25(6):1279-1294

Zhu M, Wei Y, Geissler C, Abschlag K, Corbalan Campos J, Hristov M et al (2017) Hyperlipidemia-induced microRNA-155-5p improves beta-cell function by targeting Mafb. Diabetes 66(12):3072-3084

Zhu Y, Yang T, Duan J, Mu N, Zhang T (2019) MALAT1/miR-15b-5p/MAPK1 mediates endothelial progenitor cells autophagy and affects coronary atherosclerotic heart disease via mTOR signaling pathway. Aging 11(4):1089-1109

Open Access This chapter is licensed under the terms of the Creative Commons Attribution 4.0 International License (http://creativecommons.org/licenses/by/4.0/), which permits use, sharing, adaptation, distribution and reproduction in any medium or format, as long as you give appropriate credit to the original author(s) and the source, provide a link to the Creative Commons license and indicate if changes were made.

The images or other third party material in this chapter are included in the chapter's Creative Commons license, unless indicated otherwise in a credit line to the material. If material is not included in the chapter's Creative Commons license and your intended use is not permitted by statutory regulation or exceeds the permitted use, you will need to obtain permission directly from the copyright holder.

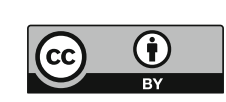

